Article

\title{
Evaluation of Rainfall Temporal Distribution Models with Annual Maximum Rainfall Events in Seoul, Korea
}

\author{
Wooyoung $\mathrm{Na} \mathbb{D}^{\mathbb{D}}$ and Chulsang Yoo *(D) \\ School of Civil, Environmental and Architectural Engineering, College of Engineering, Korea University, \\ Seoul 02841, Korea; uoo921227@gmail.com \\ * Correspondence: envchul@korea.ac.kr; Tel.: +82-10-9326-9168
}

Received: 17 September 2018; Accepted: 14 October 2018; Published: 17 October 2018

\begin{abstract}
This study evaluated five models of rainfall temporal distribution (i.e., the Yen and Chow model, Mononobe model, alternating block method, Huff model, and Keifer and Chu model), with the annual maximum rainfall events selected from Seoul, Korea, from 1961 to 2016. Three different evaluation measures were considered: the absolute difference between the rainfall peaks of the model and the observed, the root mean square error, and the pattern correlation coefficient. Also, sensitivity analysis was conducted to determine whether the model, or the randomness of the rainfall temporal distribution, had the dominant effect on the runoff peak flow. As a result, the Keifer and Chu model was found to produce the most similar rainfall peak to the observed, the root mean square error was smaller for the Yen and Chow model and the alternating block method, and the pattern correlation was larger for the alternating block method. Overall, the best model to approximate the annual maximum rainfall events observed in Seoul, Korea, was found to be the alternating block method. Finally, the sensitivity of the runoff peak flow to the model of rainfall temporal distribution was found to be much higher than that to the randomness of the rainfall temporal distribution. In particular, in small basins with a high curve number $(\mathrm{CN})$ value, the sensitivity of the runoff peak flow to the randomness of the rainfall temporal distribution was found to be insignificant.
\end{abstract}

Keywords: rainfall temporal distribution; annual maximum rainfall event; sensitivity analysis; rainfall-runoff analysis

\section{Introduction}

Once the total rainfall depth (i.e., design rainfall) is determined as a design criterion for a given return period and rainfall duration, it should be distributed temporally, to be applied in rainfall-runoff analysis. The temporal distribution of design rainfall is an important factor that affects the result of the rainfall-runoff analysis, and ultimately, the dimension of hydraulic structures. Thus, a proper model for temporally distributing the total rainfall depth should be selected, by considering the observed characteristics of the rainfall temporal distribution. The runoff peak flow and peak time are all affected by this model of rainfall temporal distribution [1].

Rainfall temporal distribution models may be categorized into three groups: The first group is composed of those derived by analyzing the observed rainfall data. The Huff model, the SCS (Soil Conservation Service) model by the NRCS (National Resources Conservation Service), the Yen and Chow model, the Mononobe model, and the Pilgrim and Cordery model are included in this group [2-6]. The second group is based on the rainfall intensity-duration-frequency (I-D-F) relation. The alternating block model, Kiefer and Chu model, and Lee and Ho model are among the models 
in this group [7-9]. The remaining models are mostly derived based on stochastic or probabilistic approaches [10-13].

Selecting one of these models of rainfall temporal distribution for application to hydrological practices is a matter of choice. For example, a dimensionless temporal distribution based on the Huff model is provided by the NOAA (National Oceanic and Atmospheric Administration) in the US [14]; this is the same in China, Singapore and South Korea [15-17]. Some countries select the model based on the I-D-F relation, like the Chicago model in New Zealand and Italy $[18,19]$ and the alternating block model in Philippines [20]. Hong Kong also used a similar method that uses the rainfall intensity information for given rainfall durations [21]. The observed temporal distribution of an extreme event is also directly considered in hydrologic analysis in Japan [22].

Verification of the selected rainfall temporal distribution model is generally carried out by comparing it with the observed rainfall events [23-27]. For example, Aron et al. (1987) evaluated the SCS model with the observed rainfall data in Pennsylvania to confirm its applicability [24]. A similar result was also found by Guo and Hargardin (2009) [25]. Nguyen et al. (2010) compared the eight models of rainfall temporal distribution to select the best one for Quebec [27]. In Korea, MOCT (Ministry of Construction and Transportation) (2000) conducted a comparison study with the Yen and Chow model, the Mononobe model, the alternating block model, the Huff model and the Keifer and Chu model and recommended the use of the Huff model in hydrological practices [28]. MLTM (Ministry of Land, Transport and Maritime Affairs) (2011) also confirmed the recommendation by MOCT (2000) [29]. Additionally, MLTM (2011) suggested that the Huff model should be derived by analyzing the rainfall events with durations longer than, or equal to, six hours [29]. It was also suggested to consider only those rainfall events whose rainfall peaks are located in the most frequent quantiles. The second or third quantile is the most frequently selected in design practice.

However, the Huff method is known to over-smooth the rainfall distribution, even though the concept of the most frequent quantile is applied. Compared to the other models of rainfall temporal distribution, the runoff peak from the Huff model is generally lower by $10 \%$ or more [30-33]. This problem becomes even more severe when the rainfall duration is short [34]. The effect of infiltration is also different, depending on the quantiles selected. The effect of infiltration is the largest for the first quantile of the Huff model, and the smallest for the fourth quantile of the model. The difference is directly reflected in the runoff peak flow and peak time. In fact, MLTM (2011) also advised choosing the third quantile, to avoid possible confusion in the selection of the most frequent rainfall quantiles [29].

This study also focused on the evaluation of the models of rainfall temporal distribution. The five models considered in MOCT (2000) and MLTM (2011) [28,29] were the Yen and Chow model, the Mononobe model, the alternating block model, the Huff model and the Keifer and Chu model were also considered. For the comparison, only the annual maximum rainfall events were used in this study, as the rainfall distribution model is mostly used for hydrological practices. The annual maximum rainfall events used in this study are those selected from Seoul, Korea from 1961 to 2016, based on bivariate frequency analysis [35]. The model and observed rainfall distribution were compared by considering the location of the rainfall peak and the randomness of the rainfall distribution. The sensitivity of the runoff peak flow to the model and randomness of the rainfall temporal distribution were also analyzed. The question was addressed of whether the model or the randomness of the rainfall temporal distribution had the dominant effect on the runoff peak flow. Finally, as a result, the best model for the rainfall temporal distribution was suggested.

\section{Models of Rainfall Temporal Distribution}

\subsection{The Yen and Chow Model}

Yen and Chow (1980) proposed a triangular-shaped temporal distribution model for the design rainfall [6]. For a basin with the design rainfall depth $R(\mathrm{~mm})$ and rainfall duration $T(\mathrm{~h})$, the rainfall 
temporal distribution (design hyetograph) is made as a triangle of area $R$ and height $h=2 R / T(\mathrm{~mm} / \mathrm{h}$ ). The peak time of rainfall can vary, which is quantified by the storm advancement coefficient. The coefficient of the storm advancement $(r)$ is defined as the ratio between the rainfall peak time and the rainfall duration. If $r=0.5$, the rainfall peak is located at the center of the rainfall event, which is called a centered type. If $r<0.5$, the rainfall event is called an advanced type, and if $r>0.5$, a delayed type.

\subsection{The Mononobe Model}

Mononobe proposed a model to distribute the design rainfall depth by analyzing the rainfall data observed in Korea [4]. This method is based on the following Equation (1), which shows the cumulative rainfall distribution up to time $t$ :

$$
R_{t}=\frac{R_{T}}{T}\left(\frac{T}{t}\right)^{n} t
$$

where $R_{T}$ is the design rainfall depth ( $\left.\mathrm{mm}\right), R_{t}$ is the cumulative rainfall depth (mm) up to time $t$, and $T$ is the rainfall duration (h). The constant $n$ is assumed to be $2 / 3$, in general. As Equation (1) is the cumulative rainfall depth, the rainfall intensity data to make the rainfall temporal distribution is derived as the difference between the current and previous time cumulative rainfall depth. After locating the rainfall peak, the next largest rainfall intensity is located alternately around the rainfall peak in turn.

\subsection{The Alternating Block Method}

The alternating block method is a method to make the rainfall temporal distribution (design hyetograph) using the rainfall intensity-duration-frequency (I-D-F) curve. After dividing the rainfall duration $T(\mathrm{~h})$ by the $\Delta t$ time-interval, the rainfall intensities for the rainfall durations $\Delta t$, $2 \Delta t, 3 \Delta t, \ldots$ are estimated from the rainfall I-D-F curve. By calculating the product of the rainfall intensity and the duration (i.e., the rainfall depth) for each rainfall duration, the cumulative rainfall distribution can be derived. The rainfall intensity data can then be obtained as the difference between the successive cumulative rainfall depths. After locating the rainfall peak at the center, the next largest rainfall intensity is located alternately to the right and left of the rainfall peak in turn, similar to the centered type Mononobe model.

\subsection{The Huff Model}

Huff (1967) analyzed the rainfall data collected over small basins in Illinois with a basin area of less than $400 \mathrm{mi}^{2}$, and proposed a model of rainfall temporal distribution [3]. This model was to choose the proper quantile by considering the frequency of the rainfall peak over the rainfall duration. Then, using only those rainfall events with peaks located at the same quantile, the rainfall temporal distribution is derived as an average rainfall distribution. This resulting rainfall temporal distribution is smooth to reflect the average rainfall distribution with time, which does not exhibit the burst characteristics of observed storms. Usually, the rainfall temporal distribution for 10, 20, . , 90 percent cumulative probabilities of occurrence are derived with the percentage of total storm rainfall for 10 percent increments of the storm duration. The 50 percent histogram represents a cumulative rainfall pattern that should be exceeded in about half of all storms. The 90 percent histogram can be interpreted as a storm distribution that is equaled or exceeded in 90 percent or less of all storms. 
When deriving the rainfall temporal distribution model, the observed rainfall events are transformed into dimensionless ones by the total rainfall depth and rainfall duration, i.e.,

$$
\begin{aligned}
& P T(i)=\frac{T(i)}{T} \times 100 \\
& P R(i)=\frac{R(i)}{R} \times 100
\end{aligned}
$$

where $P T(i)$ is the percentage of time $T(i)$ over the rainfall duration $T$, and $P R(i)$ is the percentage of the cumulative rainfall depth $R(i)$ up to the time $T(i)$ over the total rainfall depth $R$ during the rainfall duration $T$. Generally, 10 time-intervals are considered (i.e., $i=1, \ldots, 10$ ).

\subsection{The Keifer and Chu Model}

Keifer and Chu (1957) developed a synthetic hyetograph of the instantaneous intensity method type for use in sewer design for Chicago [8]. The Keifer and Chu model is also based on the rainfall I-D-F curve. That is, similarly to the alternating block method, the rainfall depth around the rainfall peak for the rainfall duration $t_{d}$ is assumed to be the same as that from the rainfall I-D-F curve. However, the rainfall intensity in the Keifer and Chu model is the instantaneous value changing continuously over the rainfall duration. That is, the difference of the Keifer and Chu model from the alternating block method is that the rainfall intensity is now considered to vary continuously throughout the storm. Hence, it is also called the instantaneous intensity model. The rainfall intensities before and after the rainfall peak time $\left(i_{a}\right.$ and $i_{b}$, respectively) are expressed as follows:

$$
\begin{gathered}
i_{a}=\frac{c\left[(1-e)\left(t_{a} / r\right)^{e}+f\right]}{\left[\left(t_{a} / r\right)^{e}+f\right]^{2}} \\
i_{b}=\frac{c\left\{(1-e)\left[t_{b} /(1-r)\right]^{e}+f\right\}}{\left\{\left[t_{b} /(1-r)\right]^{e}+f\right\}^{2}}
\end{gathered}
$$

where $t_{a}$ is the alternating time before the rainfall peak time, $t_{b}$ is the alternating time after the rainfall peak time, and $r$ is the coefficient of storm advancement; and $c, e, f$ are coefficients that vary with the return period. Also, these alternating rainfall intensities before and after the rainfall peak are assumed to make a curve.

\section{Data and Model Fitting}

\subsection{Data}

This study considered the annual maximum rainfall event data collected in Seoul, Korea, derived by Park and Yoo (2012) [36]. These annual maximum rainfall events were selected based on a bivariate frequency analysis of all the independent rainfall events that occurred in a given year. In Park and Yoo (2012), this bivariate frequency analysis was repeated every year from 1961 to 2010 [36], and in this study, additionally from 2011 to 2016. As a result, this study could consider 56 annual maximum rainfall events that covered the period from 1961 to 2016 . Figure 1 compares the rainfall histogram of those annual maximum rainfall events. All of these 56 rainfall events are different from each other. Most of them have one rainfall peak, but some have two. Also, the location of the peak varies a lot from the beginning to the end of the rainfall event. This diversity indicates that the rainfall distribution model may not easily be evaluated with the observed rainfall events. 

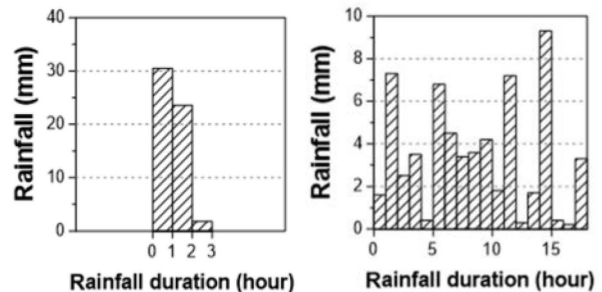

1961
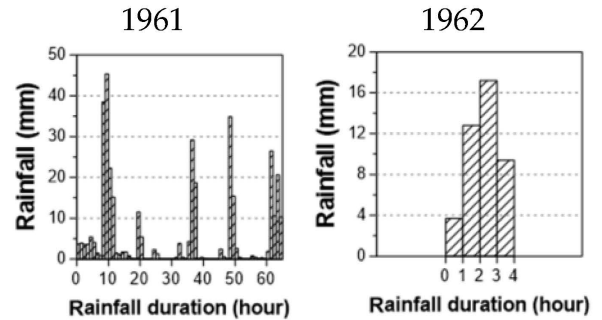

1966

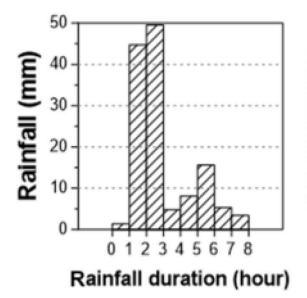

1971

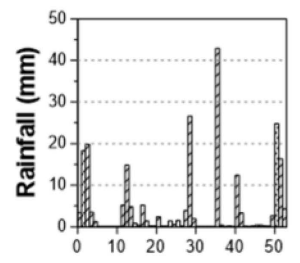

Rainfall duration (hour)

1976

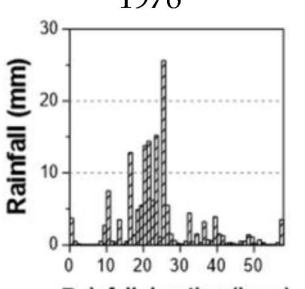

1981

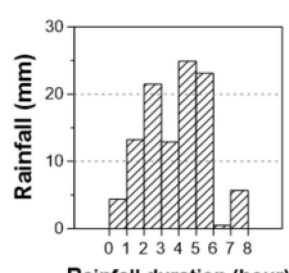

1986

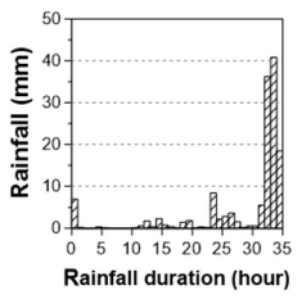

1991

1972

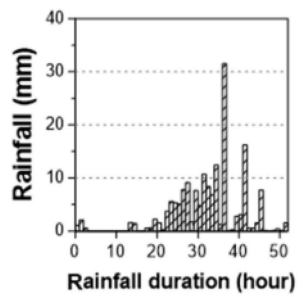

1977

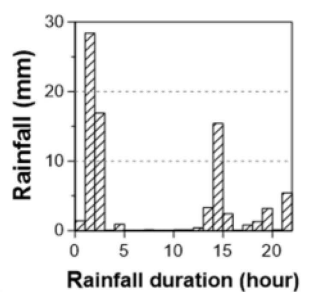

1982

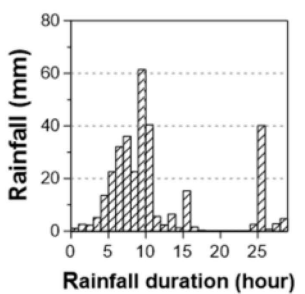

1987

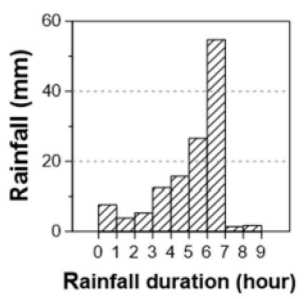

1992

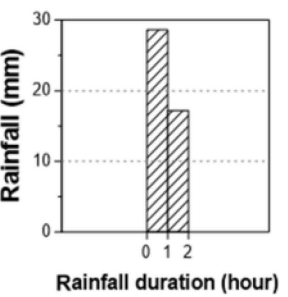

1963

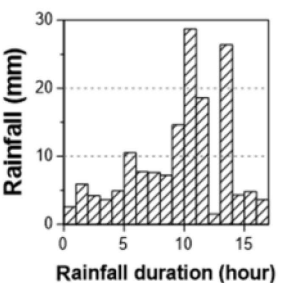

1968

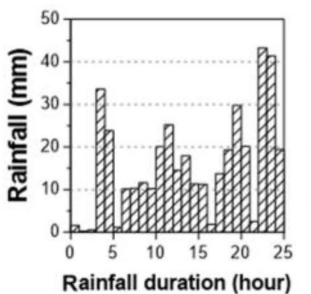

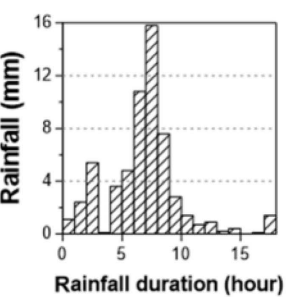

1973

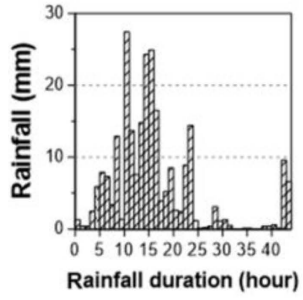

1978

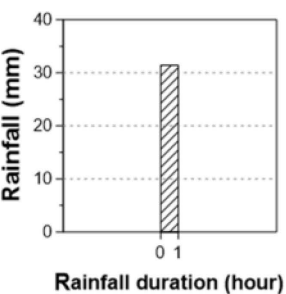

1983

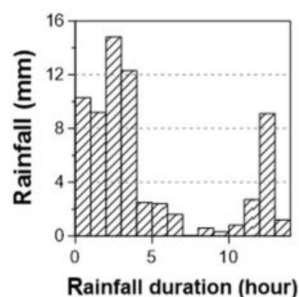

1988

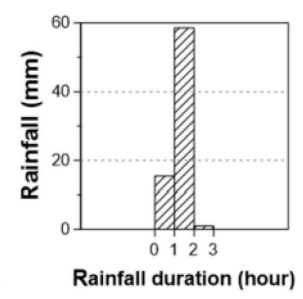

1993

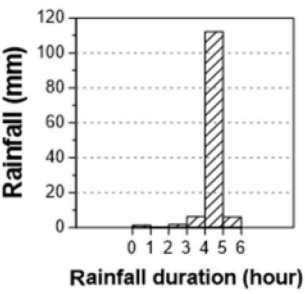

1964

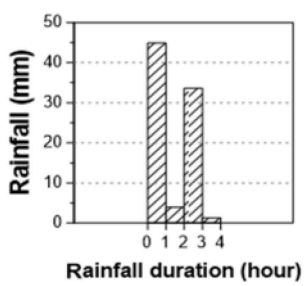

1969

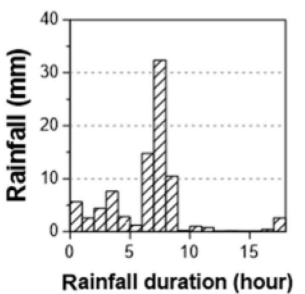

1974

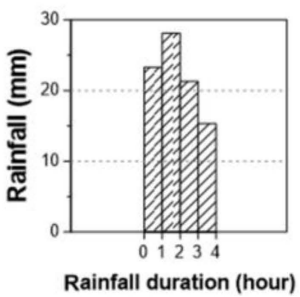

1979

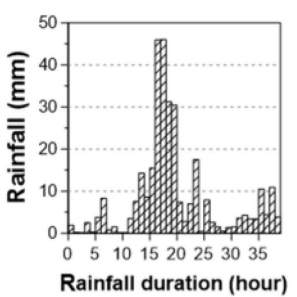

1984

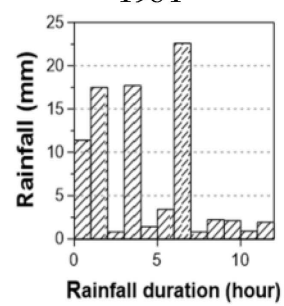

1989

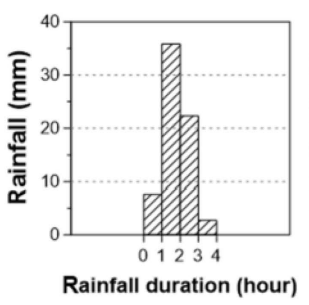

1994

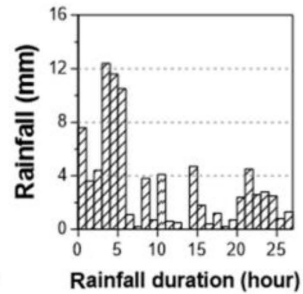

1965

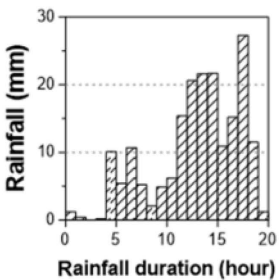

1970

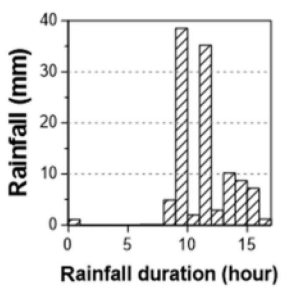

1975

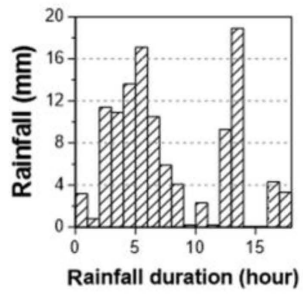

1980

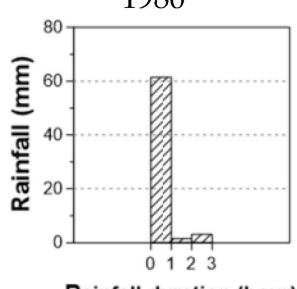

1985

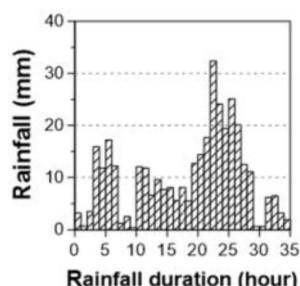

1990

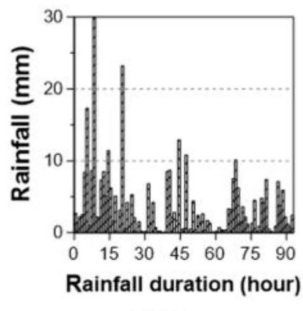

1995

Figure 1. Cont. 

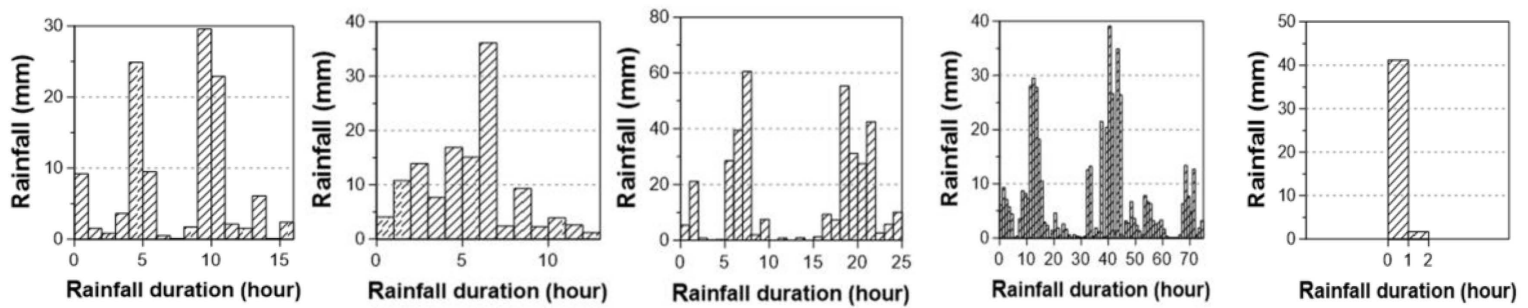

1996

1997
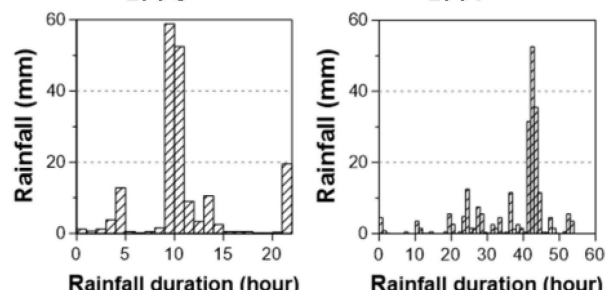

1998
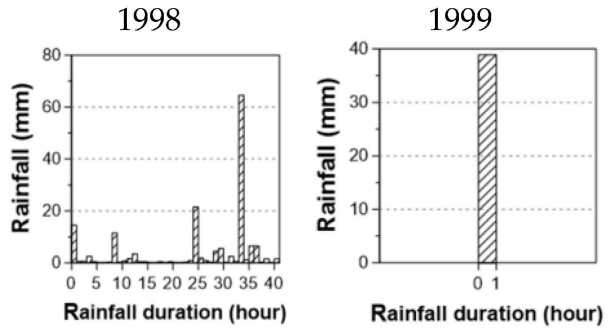

2000

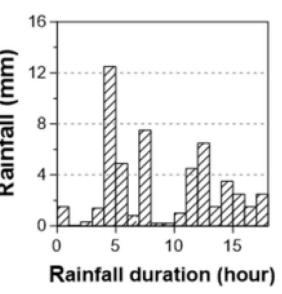

2003
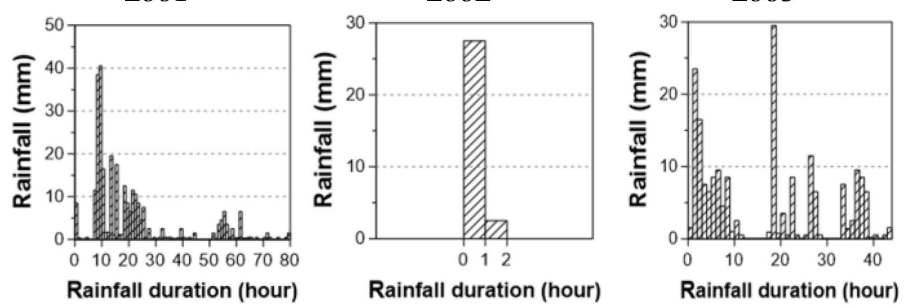

2004

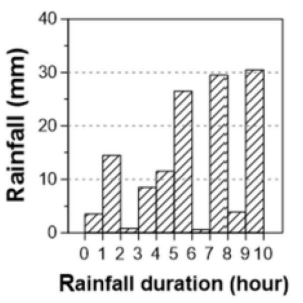

2005

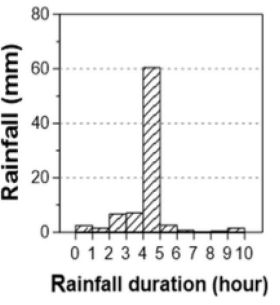

2008
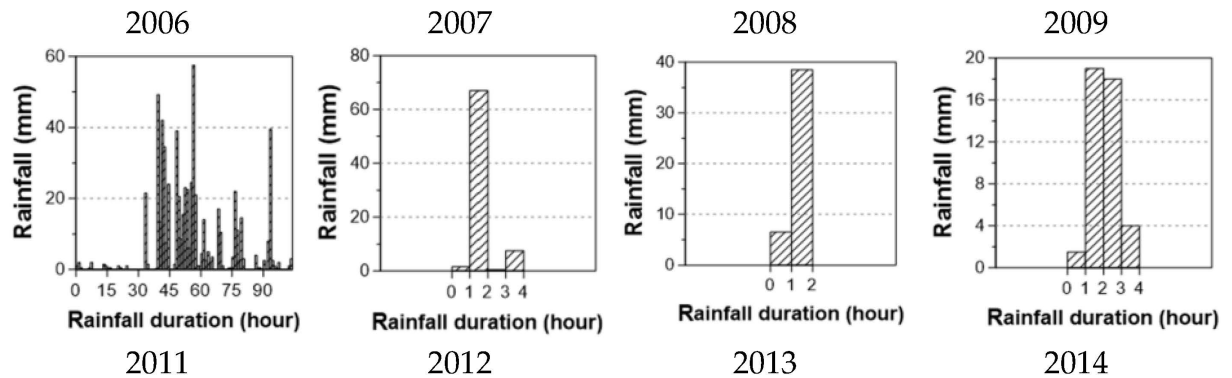

2010

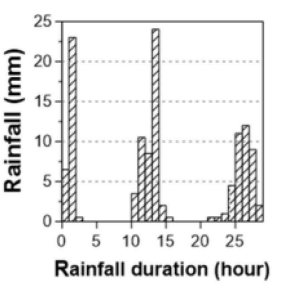

2013

2014

2015

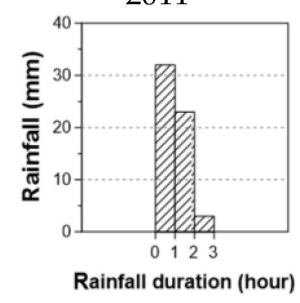

2016

Figure 1. Histograms of annual maximum rainfall events observed from 1961 to 2016 in Seoul, Korea.

Table 1 compares the selected annual maximum rainfall events with their rainfall durations, mean rainfall intensities, and total rainfall depths. Table 1 shows that the range of rainfall duration was wide, from 1 to $104 \mathrm{~h}$. The largest total rainfall depth $630 \mathrm{~mm}$ was recorded in 2011, and the smallest one was just $30 \mathrm{~mm}$ in 2007. The mean rainfall intensity also showed a wide range from $2.7 \mathrm{~mm} / \mathrm{h}$ in 1981 to $38.9 \mathrm{~mm} / \mathrm{h}$ in 2004 . The mean rainfall duration was estimated to be $24 \mathrm{~h}$, the mean rainfall intensity $11.4 \mathrm{~mm} / \mathrm{h}$, and the mean total rainfall depth $154.7 \mathrm{~mm}$. 
Table 1. Characteristics of the annual maximum rainfall events collected from 1961 to 2016 in Seoul, Korea.

\begin{tabular}{|c|c|c|c|c|c|c|c|}
\hline Year & $\begin{array}{c}\text { Rainfall } \\
\text { Duration } \\
\text { (h) }\end{array}$ & $\begin{array}{c}\text { Rainfall } \\
\text { Depth } \\
(\mathrm{mm})\end{array}$ & $\begin{array}{l}\text { Rainfall } \\
\text { Intensity } \\
(\mathrm{mm} / \mathrm{h})\end{array}$ & Year & $\begin{array}{l}\text { Rainfall } \\
\text { Duration } \\
\text { (h) }\end{array}$ & $\begin{array}{c}\text { Rainfall } \\
\text { Depth } \\
(\mathrm{mm})\end{array}$ & $\begin{array}{c}\text { Rainfall } \\
\text { Intensity } \\
(\mathrm{mm} / \mathrm{h})\end{array}$ \\
\hline 1961 & 3 & 55.9 & 18.6 & 1989 & 12 & 82.7 & 6.9 \\
\hline 1962 & 18 & 62.0 & 3.4 & 1990 & 35 & 352.2 & 10.1 \\
\hline 1963 & 2 & 45.8 & 22.9 & 1991 & 35 & 138.1 & 3.9 \\
\hline 1964 & 6 & 127.4 & 21.2 & 1992 & 9 & 129.5 & 14.4 \\
\hline 1965 & 27 & 87.0 & 3.2 & 1993 & 3 & 75.0 & 25.0 \\
\hline 1966 & 65 & 361.7 & 5.6 & 1994 & 4 & 68.4 & 17.1 \\
\hline 1967 & 4 & 43.1 & 10.8 & 1995 & 93 & 331.8 & 3.6 \\
\hline 1968 & 17 & 156.7 & 9.2 & 1996 & 16 & 116.5 & 7.3 \\
\hline 1969 & 4 & 83.7 & 20.9 & 1997 & 13 & 126.3 & 9.7 \\
\hline 1970 & 20 & 191.8 & 9.6 & 1998 & 25 & 359.7 & 14.4 \\
\hline 1971 & 8 & 132.8 & 16.6 & 1999 & 75 & 500.3 & 6.7 \\
\hline 1972 & 25 & 394.5 & 15.8 & 2000 & 2 & 42.9 & 21.5 \\
\hline 1973 & 18 & 59.5 & 3.3 & 2001 & 22 & 180.3 & 8.2 \\
\hline 1974 & 18 & 87.0 & 4.8 & 2002 & 54 & 227.9 & 4.2 \\
\hline 1975 & 17 & 112.1 & 6.6 & 2003 & 41 & 159.5 & 3.9 \\
\hline 1976 & 53 & 226.3 & 4.3 & 2004 & 1 & 38.9 & 38.9 \\
\hline 1977 & 52 & 168.2 & 3.2 & 2005 & 18 & 52.8 & 2.9 \\
\hline 1978 & 44 & 244.3 & 5.6 & 2006 & 80 & 281.3 & 3.5 \\
\hline 1979 & 4 & 88.0 & 22.0 & 2007 & 2 & 30.0 & 15.0 \\
\hline 1980 & 18 & 116.0 & 6.4 & 2008 & 44 & 192.2 & 4.4 \\
\hline 1981 & 58 & 156.2 & 2.7 & 2009 & 10 & 129.8 & 13.0 \\
\hline 1982 & 22 & 80.2 & 3.6 & 2010 & 10 & 83.5 & 8.4 \\
\hline 1983 & 1 & 31.4 & 31.4 & 2011 & 104 & 630.0 & 6.1 \\
\hline 1984 & 39 & 317.5 & 8.1 & 2012 & 4 & 76.5 & 19.1 \\
\hline 1985 & 3 & 66.0 & 22.0 & 2013 & 2 & 45.0 & 22.5 \\
\hline 1986 & 8 & 106.2 & 13.3 & 2014 & 4 & 42.5 & 10.6 \\
\hline 1987 & 29 & 323.8 & 11.2 & 2015 & 29 & 119.5 & 4.1 \\
\hline 1988 & 14 & 67.8 & 4.8 & 2016 & 3 & 58.0 & 19.3 \\
\hline
\end{tabular}

\subsection{Model Fitting}

All of the rainfall temporal distribution models considered in this study-the Yen and Chow model, Mononobe model, alternating block method, Huff model, and Keifer and Chu model—were fitted to each of the annual maximum rainfall events observed in Seoul, Korea. Six rainfall events were excluded in this application, as their durations were less than three hours. The third quantile was considered for the Huff model, which is recommended in Korea [29]. The third quantile is also the most probable quantile of the observed annual maximum rainfall events.

Somewhat different information was used for the fitting of each rainfall temporal distribution model. For example, the Yen and Chow model and Mononobe model require the total rainfall depth, but the alternating block method and Keifer and Chu model require the rainfall intensity from the rainfall I-D-F curve. The estimated return period of a rainfall event is also needed to handle the rainfall I-D-F curve. In this study, the rainfall I-D-F curve developed for the Seoul rain gauge station was used for this purpose [29]. For example, the return period of the annual maximum rainfall in 1984 was estimated to be about 11 years, and that in 2001 to be about three years.

With the estimated return period along with the total rainfall depth and rainfall duration, the rainfall temporal distribution models could be fitted for each annual maximum rainfall event. For example, Figure 2 shows the fitting results of the models to the annual rainfall events in 1984 and 2001. This figure shows that, basically, the peak time of a model is not coincident with that of the observed. This result is quite natural, considering the randomness of the peak time. Concerning the rainfall peak, the Huff model derived a smaller rainfall peak than the observed, which was also the same for the Yen and Chow model. The rainfall peak of the alternating block method and that of the 
Keifer and Chu model were found to be quite similar to the observed, while that of the Mononobe model was found to be much higher than the observed.

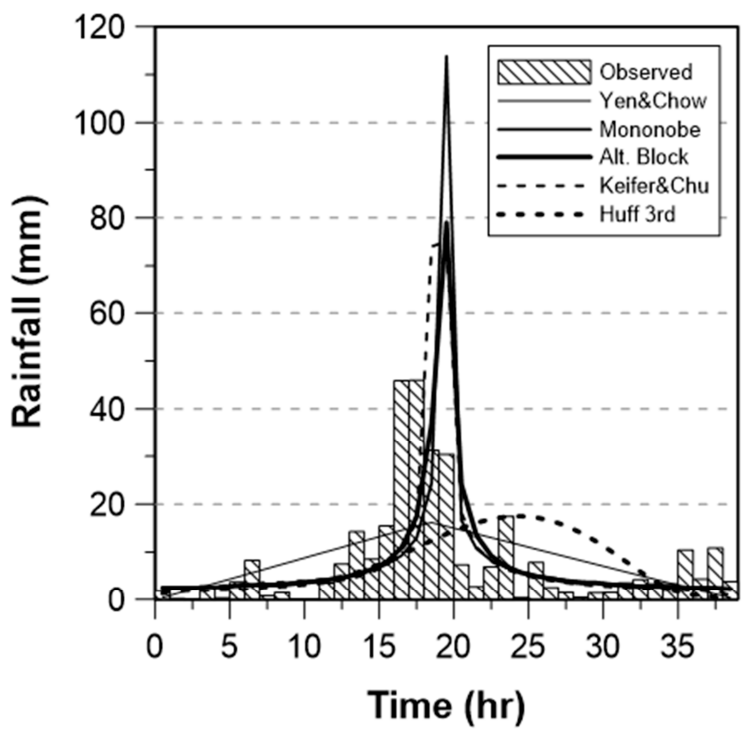

(a) 1984

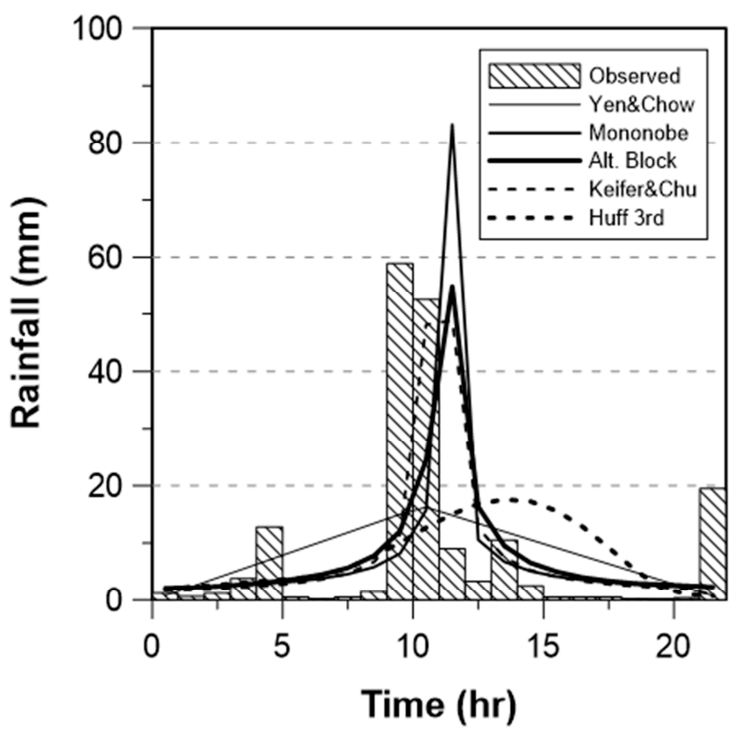

(b) 2001

Figure 2. Comparison of the rainfall temporal distribution models and observed annual maximum rainfall events in 1981 (a) and in 2004 (b) (Case 1).

\section{Evaluation of the Rainfall Temporal Distribution Models}

\subsection{Evaluation Methods and Evaluation Measures}

In this part of the study, the rainfall temporal distribution models were evaluated by comparing them to the observed annual maximum rainfall events in Seoul, Korea. This study considered three different cases for the evaluation. The first case (Case 1) was to compare the model and the observed rainfall event as it is. The second case (Case 2) was to compare the model and observed rainfall event, after reconciling the rainfall peak time of the specific model to the observed. That is, by moving the rainfall temporal distribution of the model in parallel, it is possible to fix the rainfall peak time of the model to the observed. The third case (Case 3) was to compare the model and observed rainfall event, after rearranging the observed rainfall temporal distribution to be most similar to the model. In this case, the randomness of the observed rainfall temporal distribution is removed, to make its temporal distribution most approximate that of the specific model.

In fact, the rearrangement of the rainfall temporal distribution of the third case may cause a distortion of the autocorrelation structure of an observed rainfall event [37]. However, after the rearrangement, mean autocorrelation coefficients of observed rainfall events and rainfall temporal distribution models were found to be similar to each other. That is, the mean autocorrelation coefficient of all the rainfall events considered in this study was about 0.35 , but became about 0.65 after the rearrangement. The mean autocorrelation coefficient of the five rainfall temporal distribution models considered in this study was estimated to be about 0.56 . The effect of randomness in the rainfall temporal distribution will also be evaluated in Section 5.3 with an emphasis on the runoff calculation.

Three different evaluation measures were considered in this study. The first measure was the absolute difference between the rainfall peaks of the model and the observed $\left(D R_{p e a k}\right)$, which is defined as follows:

$$
D R_{\text {peak }}=\left|S_{p}-O_{p}\right|
$$

where $S_{p}$ is the rainfall peak of the model, and $O_{p}$ is the observed. The second measure is the root mean square error (RMSE). This RMSE can be assumed as the standard deviation of the differences 
between the model and the observed rainfall temporal distribution. The RMSE is calculated using the following equation:

$$
R M S E=\sqrt{\frac{\sum_{i=1}^{n}\left(S_{i}-O_{i}\right)^{2}}{n}}
$$

where $S_{i}$ is the rainfall intensity at time $i$ of the model, and $O_{i}$ is the observed rainfall intensity at time $i$.

Finally, the third measure is the pattern correlation coefficient $(R)$. This pattern correlation coefficient is a correlation coefficient to measure the similarity of the pair data. The pattern correlation coefficient is calculated as follows:

$$
R=\frac{\sum_{i=1}^{n}\left(S_{i}-\bar{S}\right)\left(O_{i}-\bar{O}\right)}{\sqrt{\sum_{i=1}^{n}\left(S_{i}-\bar{S}\right)^{2}} \sqrt{\sum_{i=1}^{n}\left(O_{i}-\bar{O}\right)^{2}}}
$$

where $\bar{S}$ and $\bar{O}$ represent the means of the model and the observed rainfall temporal distribution.

\subsection{Evaluation Results}

As mentioned in the previous section, three different cases were considered for the evaluation of the rainfall temporal distribution models. Figure 2 is for Case 1 for the annual maximum rainfall events observed in 1984 and 2001. Case 2 and Case 3 are presented in Figures 3 and 4, respectively.

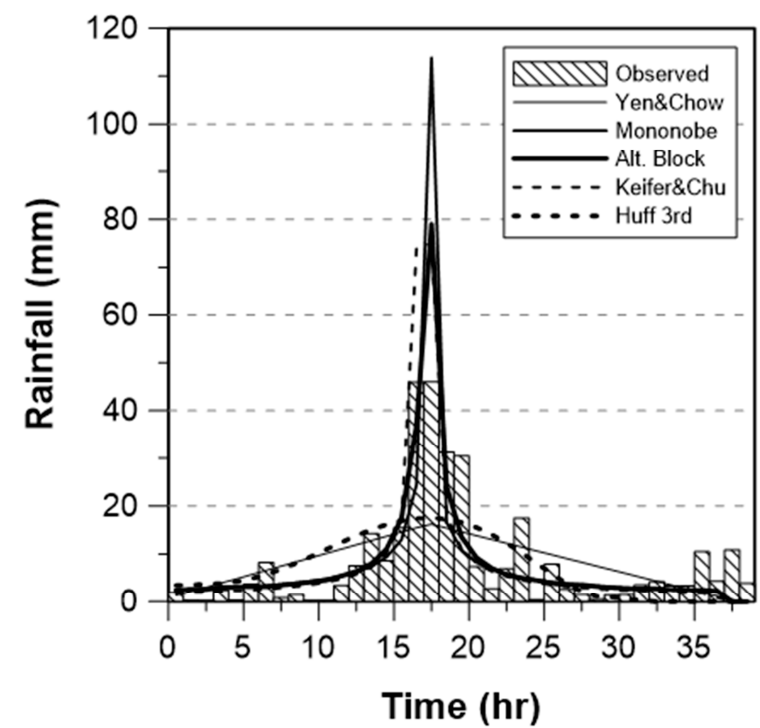

(a) 1984

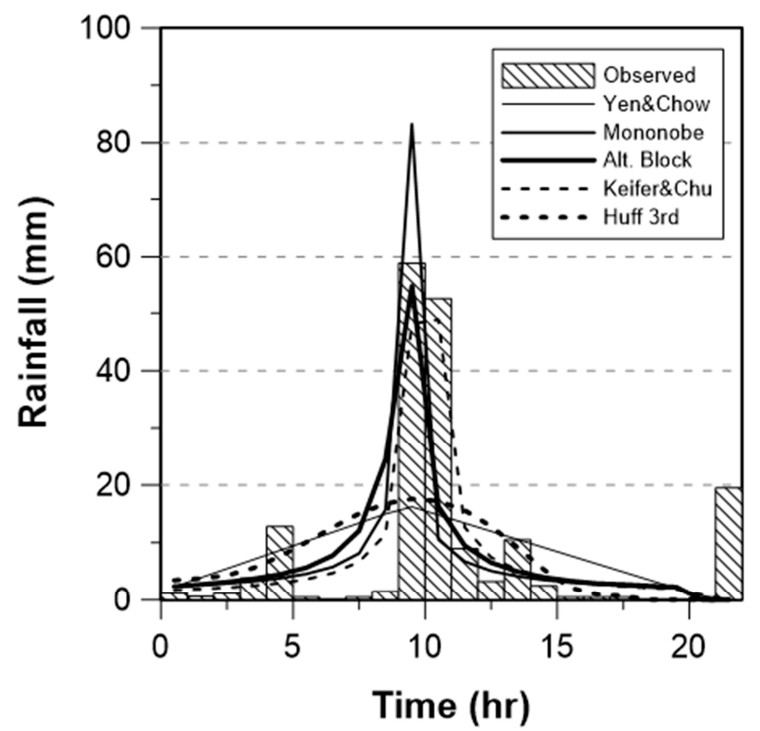

(b) 2001

Figure 3. As for Figure 2, but for Case 2.

Table 2 summarizes the evaluation results with the annual maximum rainfall events in 1984 and 2001. For each model, $D R_{\text {peak }}$ should be estimated to be the same for Cases 1, 2 and 3 . Additionally, a positive (or negative) sign was given to the value of $D R_{\text {peak }}$ to distinguish the higher (or lower) rainfall peak of a model from the observed. As the rainfall peak of the Yen and Chow model and the Huff model was mostly smaller than the observed, a negative sign was given to the estimates of $D R_{\text {peak }}$. On the other hand, a positive sign was given to the results of the Mononobe model application. 


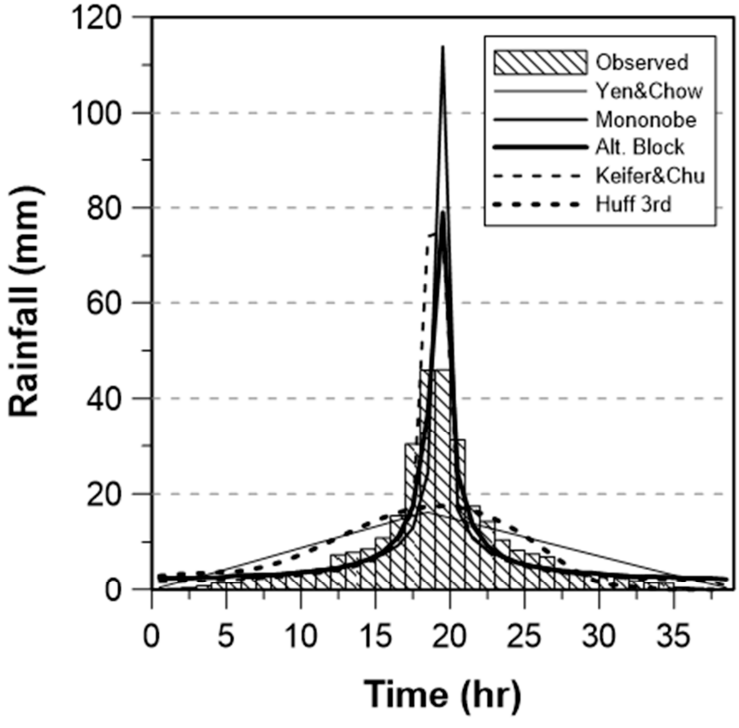

(a) 1984

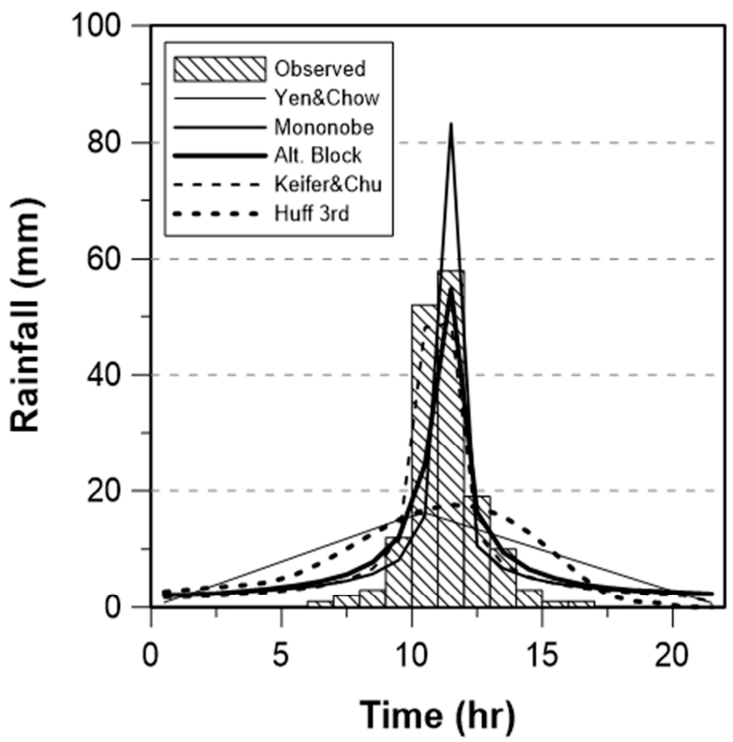

(b) 2001

Figure 4. As for Figure 2, but for Case 3.

The RMSEs for the application of the alternating block method and the Keifer and Chu model were estimated to be smaller than for the other model applications. As can be expected, the RMSE for Case 1 was the largest, and that for Case 3 was the smallest. This result was also the same for the pattern correlation coefficient. The highest value of the pattern correlation coefficient was obtained in the application of the alternating block method and the Keifer and Chu model, and the lowest value in the application of the Mononobe model. Overall, among the five models considered in this study, the alternating block method and the Keifer and Chu model were found to be most similar to the observed.

Table 2. Evaluation results of rainfall temporal distribution models with the maximum rainfall events observed in 1984 and 2001.

\begin{tabular}{|c|c|c|c|c|c|c|c|}
\hline $\begin{array}{c}\text { Evaluation } \\
\text { Measure }\end{array}$ & Year & Case & $\begin{array}{c}\text { Yen and } \\
\text { Chow }\end{array}$ & Mononobe & $\begin{array}{l}\text { Alternating } \\
\text { Block }\end{array}$ & $\begin{array}{l}\text { Keifer } \\
\text { and Chu }\end{array}$ & Huff \\
\hline \multirow{2}{*}{$D R_{\text {peak }}$} & 1984 & - & -29.8 & 67.8 & 33.0 & 29.0 & -28.5 \\
\hline & 2001 & - & -42.7 & 24.4 & -4.0 & -10.0 & -41.3 \\
\hline \multirow{6}{*}{ RMSE } & \multirow{3}{*}{1984} & 1 & 9.45 & 16.13 & 11.73 & 13.17 & 11.47 \\
\hline & & 2 & 9.51 & 12.86 & 6.57 & 8.44 & 9.48 \\
\hline & & 3 & 8.30 & 12.20 & 6.32 & 7.53 & 8.13 \\
\hline & \multirow{3}{*}{2001} & 1 & 14.28 & 21.34 & 16.27 & 14.34 & 15.79 \\
\hline & & 2 & 14.05 & 11.89 & 10.55 & 4.81 & 14.62 \\
\hline & & 3 & 13.33 & 9.93 & 6.57 & 3.35 & 13.05 \\
\hline \multirow{6}{*}{$R$} & \multirow{3}{*}{1984} & 1 & 0.58 & 0.45 & 0.56 & 0.58 & 0.24 \\
\hline & & 2 & 0.59 & 0.70 & 0.83 & 0.86 & 0.61 \\
\hline & & 3 & 0.77 & 0.73 & 0.88 & 0.90 & 0.79 \\
\hline & \multirow{3}{*}{2001} & 1 & 0.46 & 0.14 & 0.33 & 0.52 & 0.19 \\
\hline & & 2 & 0.45 & 0.73 & 0.73 & 0.92 & 0.50 \\
\hline & & 3 & 0.64 & 0.82 & 0.93 & 0.99 & 0.50 \\
\hline
\end{tabular}


To summarize the evaluation results for all annual maximum rainfall events, $D R_{\text {peak }}$ and RMSE were standardized. That is, the $D R_{\text {peak }}$ was divided by the observed rainfall peak $\left(O_{\text {peak }}\right)$ of the rainfall event to create the standardized $S D R_{\text {peak }}$, and the RMSE was divided by the mean rainfall intensity (I) to make the standardized SRMSE. That is,

$$
\begin{aligned}
& S D R_{\text {peak }}=\frac{D R_{\text {peak }}}{O_{\text {peak }}} \\
& S R M S E=\frac{R M S E}{I}
\end{aligned}
$$

Table 3 summarizes the $S D R_{\text {peak }}$, SRMSE, and $R$ for all 50 annual maximum rainfall events by their mean and standard deviation. Similarly to the $D R_{\text {peak }}$, the $S D R_{\text {peak }}$ of each rainfall event was estimated to be the same for all cases, but the SRMSE and $R$ were estimated differently for each case. The sign of $S D R_{\text {peak }}$ was determined by following the same rule as for $D R_{\text {peak }}$.

Table 3. Evaluation results of rainfall temporal distribution models with all the annual maximum

\begin{tabular}{|c|c|c|c|c|c|c|}
\hline $\begin{array}{l}\text { Evaluation } \\
\text { Measure }\end{array}$ & Case & $\begin{array}{l}\text { Yen and } \\
\text { Chow }\end{array}$ & Mononobe & $\begin{array}{l}\text { Alternating } \\
\text { Block }\end{array}$ & $\begin{array}{c}\text { Keifer and } \\
\text { Chu }\end{array}$ & Huff \\
\hline$S D R_{\text {peak }}$ & - & $\begin{array}{l}-0.499 \\
(0.240)\end{array}$ & $\begin{array}{c}0.706 \\
(0.593)\end{array}$ & $\begin{array}{c}0.548 \\
(0.453)\end{array}$ & $\begin{array}{c}0.473 \\
(0.419)\end{array}$ & $\begin{array}{l}-0.467 \\
(0.245)\end{array}$ \\
\hline \multirow{3}{*}{ SRMSE } & 1 & $\begin{array}{c}1.337 \\
(0.592)\end{array}$ & $\begin{array}{c}1.894 \\
(0.731)\end{array}$ & $\begin{array}{l}1.810 \\
(0.793)\end{array}$ & $\begin{array}{c}2.012 \\
(1.000)\end{array}$ & $\begin{array}{c}1.398 \\
(0.572)\end{array}$ \\
\hline & 2 & $\begin{array}{c}1.242 \\
(0.628)\end{array}$ & $\begin{array}{c}1.299 \\
(0.629)\end{array}$ & $\begin{array}{l}1.296 \\
(0.717)\end{array}$ & $\begin{array}{c}1.592 \\
(0.986)\end{array}$ & $\begin{array}{c}1.189 \\
(0.616)\end{array}$ \\
\hline & 3 & $\begin{array}{c}0.955 \\
(0.557)\end{array}$ & $\begin{array}{c}0.914 \\
(0.310)\end{array}$ & $\begin{array}{c}0.754 \\
(0.386)\end{array}$ & $\begin{array}{c}1.135 \\
(0.794)\end{array}$ & $\begin{array}{l}1.039 \\
(0.544)\end{array}$ \\
\hline \multirow{3}{*}{$R$} & 1 & $\begin{array}{c}0.268 \\
(0.337)\end{array}$ & $\begin{array}{c}0.208 \\
(0.264)\end{array}$ & $\begin{array}{c}0.238 \\
(0.259)\end{array}$ & $\begin{array}{c}0.304 \\
(0.266)\end{array}$ & $\begin{array}{c}0.170 \\
(0.350)\end{array}$ \\
\hline & 2 & $\begin{array}{c}0.508 \\
(0.304)\end{array}$ & $\begin{array}{c}0.733 \\
(0.173)\end{array}$ & $\begin{array}{c}0.732 \\
(0.196)\end{array}$ & $\begin{array}{c}0.610 \\
(0.252)\end{array}$ & $\begin{array}{c}0.541 \\
(0.285)\end{array}$ \\
\hline & 3 & $\begin{array}{c}0.751 \\
(0.171)\end{array}$ & $\begin{array}{c}0.804 \\
(0.126)\end{array}$ & $\begin{array}{c}0.877 \\
(0.100)\end{array}$ & $\begin{array}{c}0.743 \\
(0.201)\end{array}$ & $\begin{array}{c}0.629 \\
(0.207)\end{array}$ \\
\hline
\end{tabular}
rainfall events considered in this study (mean value along with standard deviation inside the bracket).

As a result, the $S D R_{\text {peak }}$ shows that the Yen and Chow model and the Huff model tend to underestimate the rainfall peak, while the Mononobe model tends to overestimate. Among the five models considered in this study, the Keifer and Chu model produced the most similar rainfall peak to the observed. On the other hand, the smallest SRMSEs were estimated for the Yen and Chow model and the alternating block method. The value of $R$ was larger for the alternating block method, but smaller for the Yen and Chow model and the Huff model. In particular, in Case 3, the alternating block method showed the smallest SRMSE and largest $R$, which indicates that it is the most similar model to the observed rainfall temporal distribution.

\section{Sensitivity of the Runoff Peak to the Rainfall Temporal Distribution}

\subsection{Preparation of the Rainfall-Runoff Model}

In this part of the study, the sensitivity of the runoff peak to the rainfall temporal distribution was evaluated. The sensitivity analysis was repeated two times; once on the models of the rainfall temporal distribution, and once on the randomness of the rainfall temporal distribution. Here, the randomness of the rainfall distribution indicates the transformation of the rainfall temporal distribution from Case 3 to Case 2 or Case 1. In contrast to the very well-organized design for rainfall based on the rainfall 
temporal distribution model, the observed rainfall event shows very random organization of the rainfall intensity values over the rainfall duration.

This study used the 1-h unit hydrograph (UH) for the rainfall-runoff analysis. The UH was derived using the Clark instantaneous unit hydrograph (IUH), whose two parameters-the concentration time $T_{c}$ and storage coefficient $K$-were assumed to be the same. Three different UHs were derived with the concentration time 1,3 , and $5 \mathrm{~h}$. The basin area was also assumed to be linearly proportional to the concentration time. Figure 5 compares the three UHs. In particular, it shows that the peak flow is not proportional to the basin area.

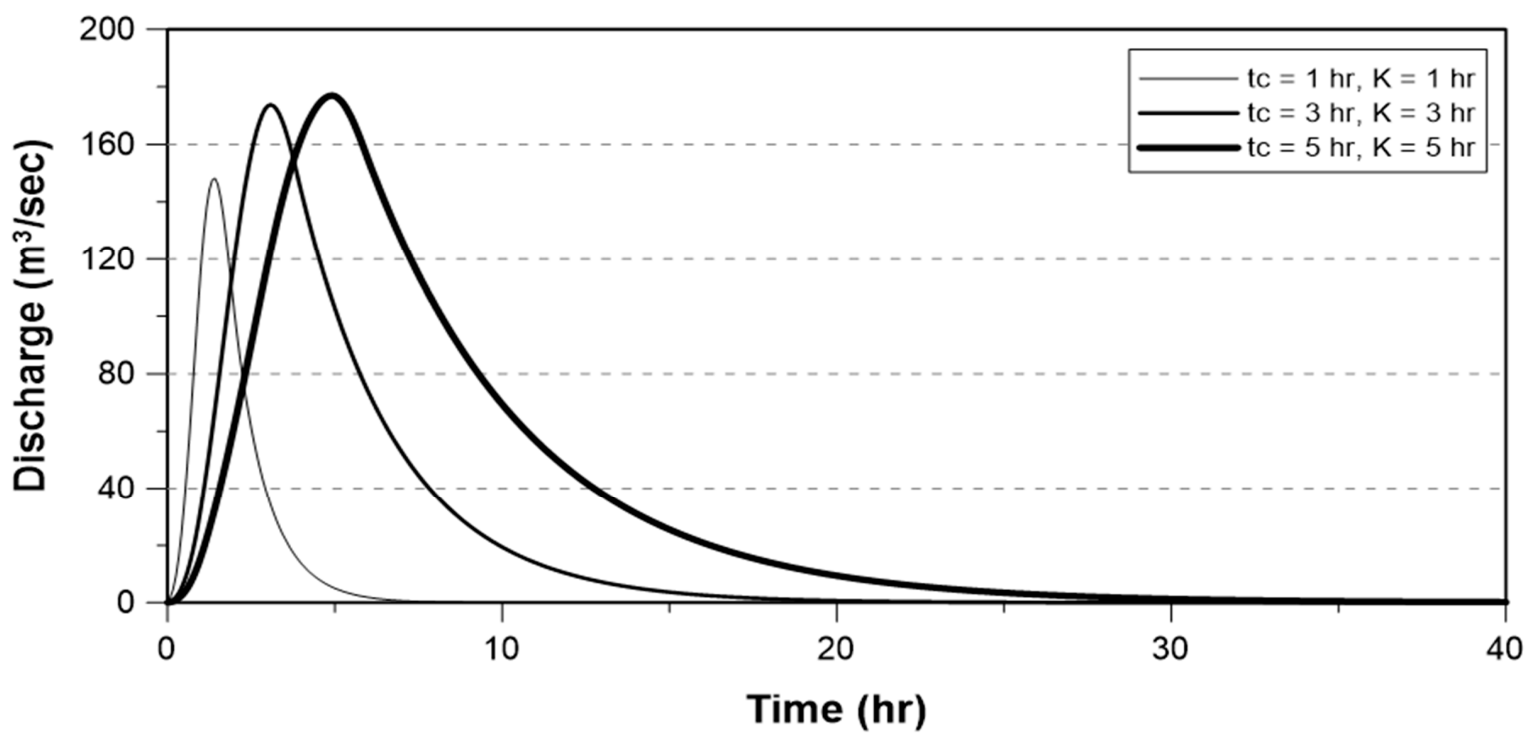

Figure 5. Comparison of 1-h unit hydrographs derived for the three artificial basins.

The infiltration loss was considered in the rainfall-runoff analysis by the NRCS-CN (National Resources Conservation Service-Curve Number) method [38]. Three different CN values of 60, 80 and 100 were considered, to consider the different land cover and soil characteristics. The higher the CN value, the larger the effective rainfall amount. The $\mathrm{CN} 100$ indicates no infiltration, while the $\mathrm{CN}$ value 0 indicates no effective rainfall.

\subsection{Sensitivity to the Rainfall Temporal Distribution Models}

Each model considered in this study derives a different rainfall temporal distribution, which is also related to the shape of the runoff hydrograph. Additionally, the infiltration characteristics (i.e., $\mathrm{CN}$ ), as well as the runoff characteristics (i.e., $T_{c}$ and $K$ ), will also change the shape of the runoff hydrograph. To evaluate this difference caused by applying a different model of rainfall temporal distribution, this study performed the rainfall-runoff analysis with different basin and infiltration characteristics. The annual maximum rainfall event that occurred in 1997 was considered as an example case. This rainfall event was continued for $13 \mathrm{~h}$, and the mean rainfall intensity was $9.7 \mathrm{~mm} / \mathrm{h}$. The return period of this rainfall event was estimated to be two years.

With the mean rainfall intensity and the rainfall duration of the rainfall event in 1997, five different rainfall temporal distributions were derived. Also, by considering three different $\mathrm{CN}$ values and three different UHs, a total of nine combinations could be prepared for each model of rainfall temporal distribution. That is, for each $\mathrm{UH}, 15$ combinations of rainfall distributions and $\mathrm{CNs}$ were prepared. Table 4 summarizes these combinations for the rainfall-runoff analysis. 
Table 4. Combinations of five rainfall temporal distribution models, three $\mathrm{CN}$ values and three $T_{\mathcal{C}}(=K)$ values considered in this study.

\begin{tabular}{ccc}
\hline Model & $\mathbf{C N}$ & $T_{c}=K(\mathbf{h})$ \\
\hline $\begin{array}{c}\text { Yen and Chow } \\
\text { Mononobe }\end{array}$ & 60 & 1 \\
\hline Alternating Block & 80 & 3 \\
\hline $\begin{array}{c}\text { Keifer and Chu } \\
\text { Huff }\end{array}$ & 100 & 5 \\
\hline
\end{tabular}

First, Figure 6 compares the 15 histograms of effective rainfall with the different rainfall temporal distributions and CNs. As can be expected, the effect of the CNs is concentrated in the early part of the rainfall, but the effective rainfall peak was also decreased a bit with higher $\mathrm{CN}$. Second, Figure 7 compares the runoff hydrographs derived by applying the 1-h UH. This figure shows that the runoff hydrographs were considerably affected by the $\mathrm{CN}$ value and the $\mathrm{UH}$. The runoff hydrographs were all derived as would be expected.

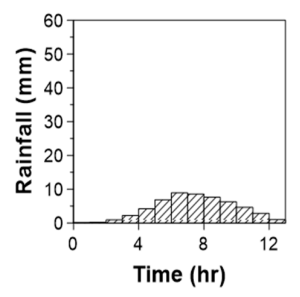

Yen and Chow

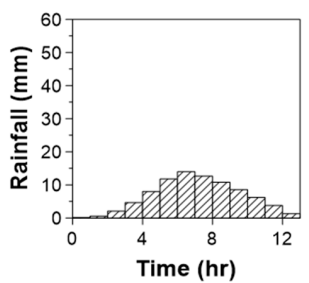

Yen and Chow

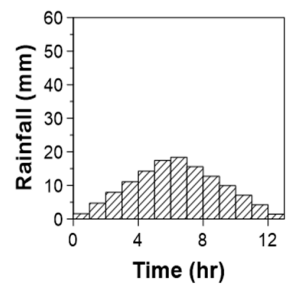

Yen and Chow

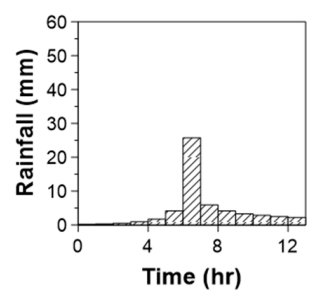

Mononobe

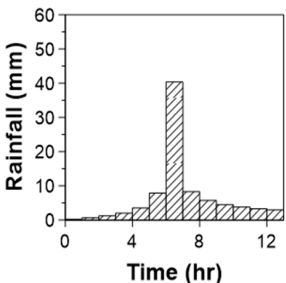

Mononobe

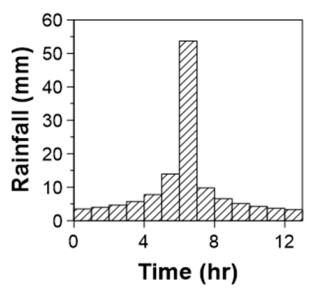

Mononobe

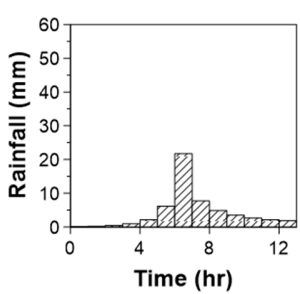

Alternating block

(a) $\mathrm{CN}=60$

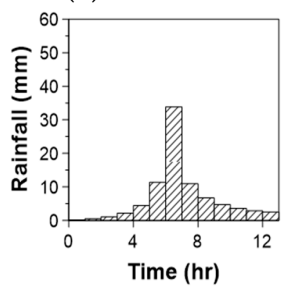

Alternating block

(b) $\mathrm{CN}=80$

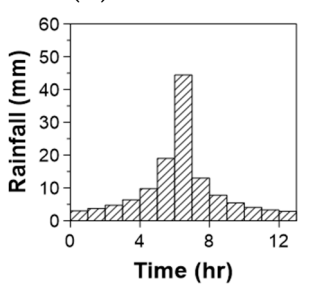

Alternating block

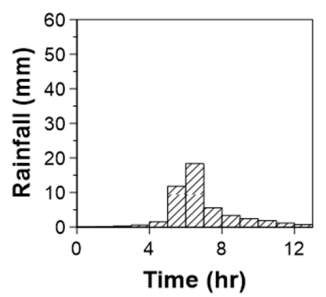

Keifer and Chu

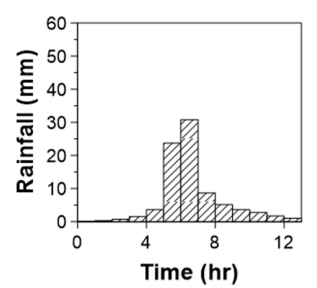

Keifer and Chu

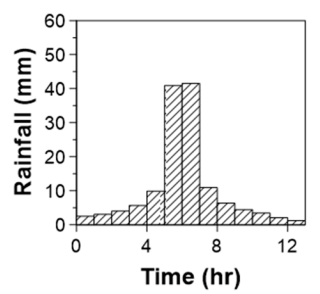

Keifer and Chu

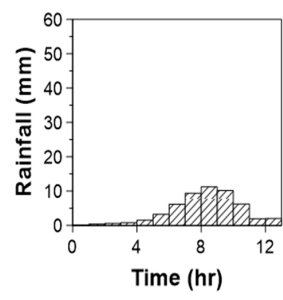

Huff

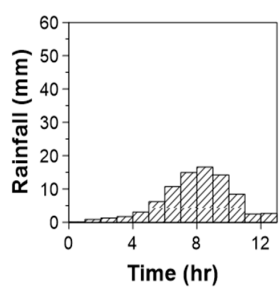

Huff

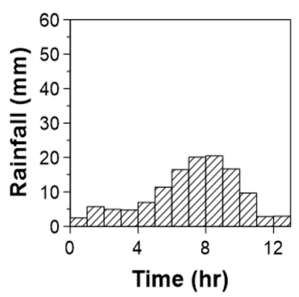

Huff

(c) $\mathrm{CN}=100$

Figure 6. Comparison of effective rainfall temporal distributions of model and the annual maximum rainfall event in 1997.

The key result of Figure 7 lies in the effect of the model of rainfall temporal distribution. First, the Yen and Chow model and the Huff model produced a far smaller peak flow than the other models. In particular, the sensitivity of the peak flow to the model of rainfall temporal distribution was higher for the case with small $T_{\mathcal{c}}$ and $K$. For the case with larger $T_{\mathcal{c}}$ and $K$, the sensitivity to the model was found to be much smaller. The peak flow derived by applying the Mononobe model was the highest, but was also similar to that of the Keifer and Chu model. 


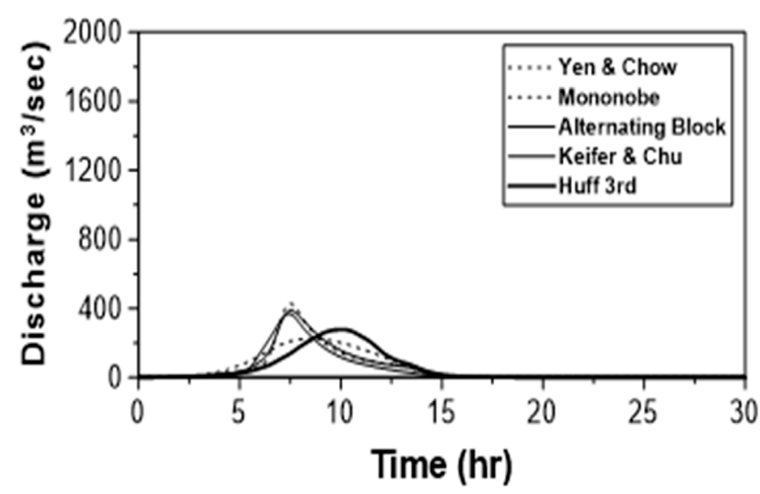

$T_{c}, K=1 \mathrm{~h}$

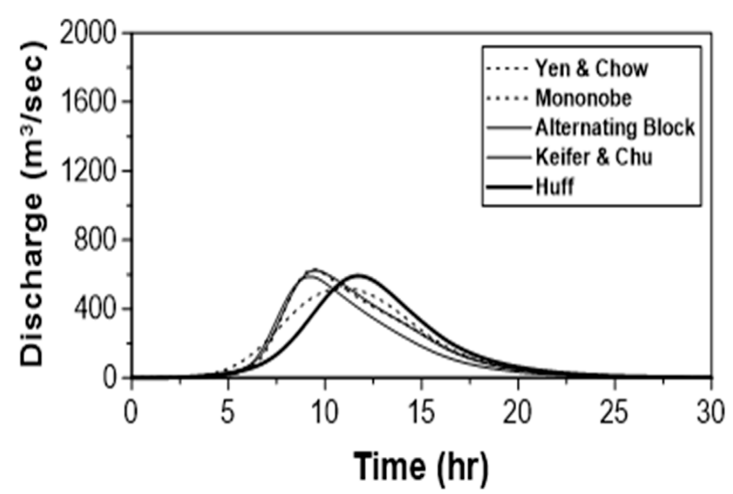

$T_{c}, K=3 \mathrm{~h}$

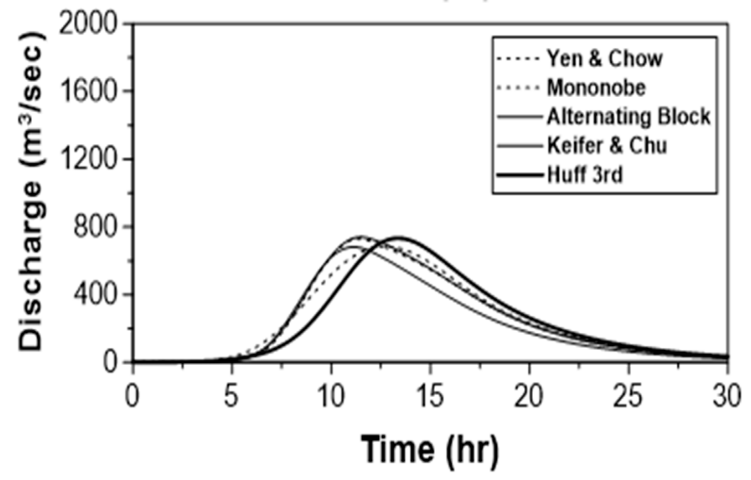

$T_{c}, K=5 \mathrm{~h}$

(a) $\mathrm{CN}=60$

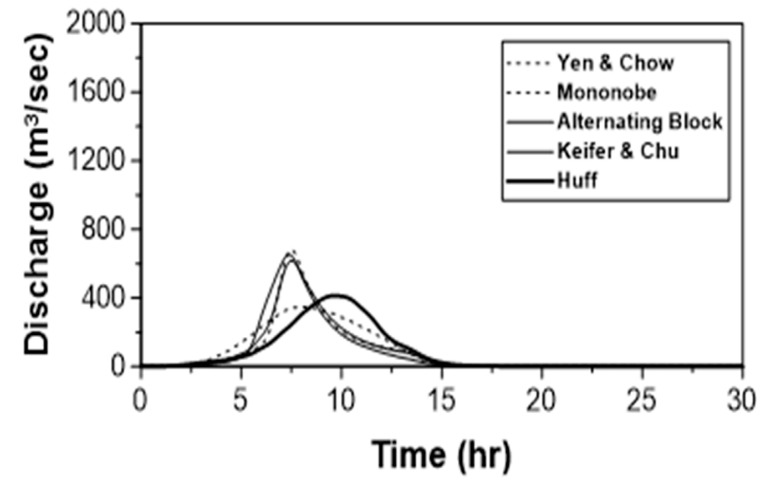

$T_{c}, K=1 \mathrm{~h}$

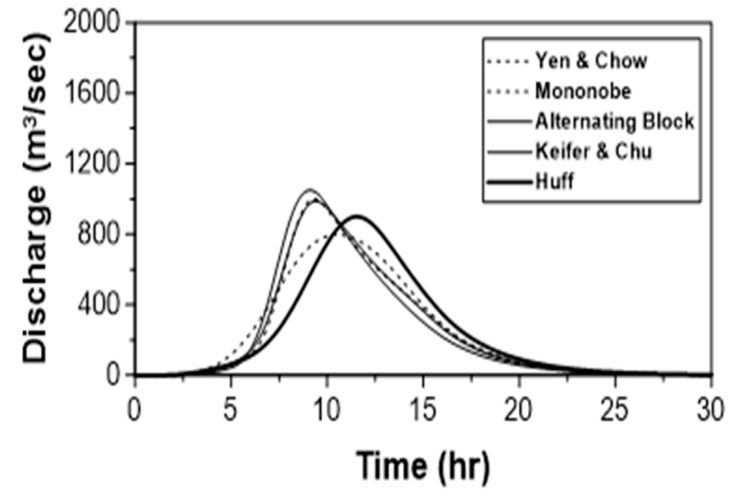

$T_{c}, K=3 \mathrm{~h}$

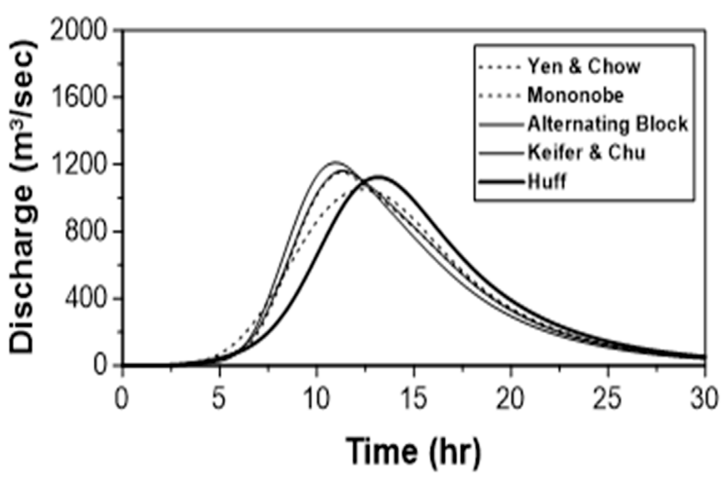

$T_{c}, K=5 \mathrm{~h}$

(b) $\mathrm{CN}=80$

Figure 7. Cont. 


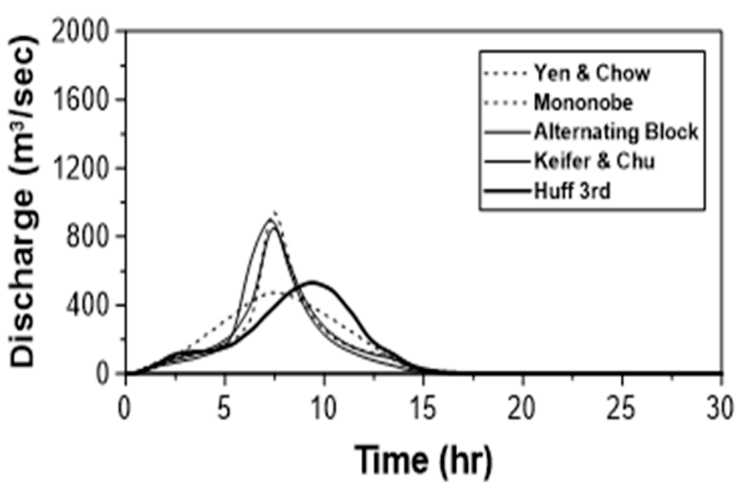

$T_{c}, K=1 \mathrm{~h}$

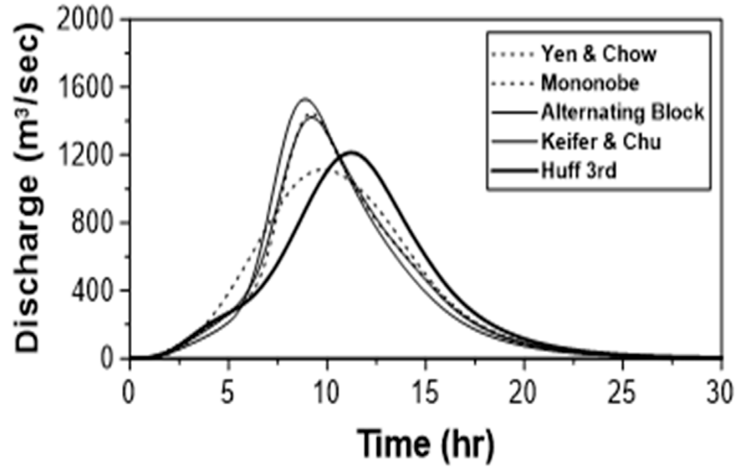

$T_{c}, K=3 \mathrm{~h}$

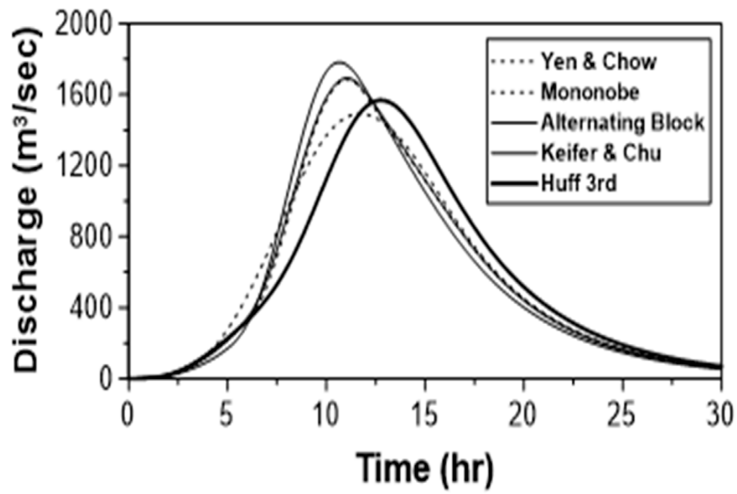

$T_{c}, K=5 \mathrm{~h}$

(c) $\mathrm{CN}=100$

Figure 7. Comparison of runoff hydrographs derived with different rainfall temporal distribution models for the annual maximum rainfall event in 1997.

The above results can also be evaluated quantitatively from the point of the sensitivity of the peak flow to the model of rainfall temporal distribution. For this purpose, the following measure, a ratio of the peak flow of a model to the mean of all five models (Ratio peak), was introduced:

$$
\text { Ratio }_{\text {peak }}=\frac{O_{\text {peak }}}{\bar{O}_{\text {peak }}}
$$

where $O_{\text {peak }}$ is the peak flow of a model, and $\bar{O}_{\text {peak }}$ is the mean of the peak flows of the five models of rainfall temporal distribution. Figure 8 summarizes the results in box plots.

This figure shows that the sensitivity of the peak flow to the model of rainfall temporal distribution became much larger in a small basin (where the concentration time is short). The inter-quantile range estimated for the case of $T_{c}=1 \mathrm{~h}$ was estimated to be more than three times of that for the case of $T_{c}=3$ or $5 \mathrm{~h}$. On the other hand, the difference between the two cases of $T_{c}=3 \mathrm{~h}$ and $T_{c}=5 \mathrm{~h}$ was very small. As the rainfall distribution was made at hourly intervals, the effect of the rainfall peak on the peak flow seems to be direct for the case of $T_{\mathcal{c}}=1 \mathrm{~h}$. On the other hand, in the case of longer $T_{\mathcal{C}}$, the storage effect significantly dampened the effect of the rainfall peak.

$\mathrm{CN}$ also seemed to have a significant effect on the peak flow, even though that effect was not as high as that of the concentration time. As the $\mathrm{CN}$ value increased, the inter-quantile range of the box plot increased, which was also obvious for the cases of $T_{c}=3 \mathrm{~h}$ and $T_{c}=5 \mathrm{~h}$. For the case of $T_{c}=1 \mathrm{~h}$, the effect of $\mathrm{CN}$ seemed to be minimum. This result indicates that as the basin area increases, the sensitivity of the peak flow to the model of rainfall temporal distribution becomes smaller. More generally, the effect of rainfall distribution on the rainfall-runoff model for a small basin 
with small $T_{\mathcal{c}}$ and $K$ can be very limited. On the other hand, in a large basin with larger $T_{\mathcal{c}}$ and $K$, the effect of $\mathrm{CN}$ could be seen more clearly.

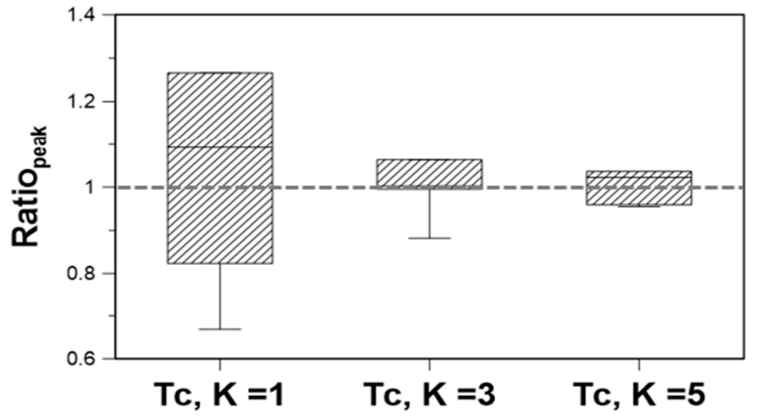

(a) $\mathrm{CN}=60$

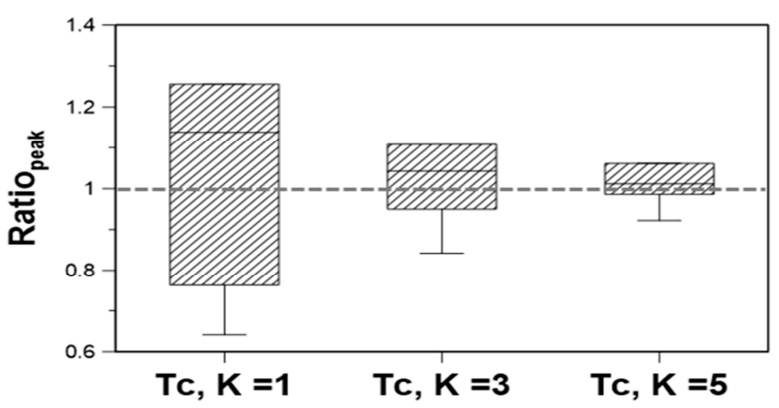

(b) $\mathrm{CN}=80$

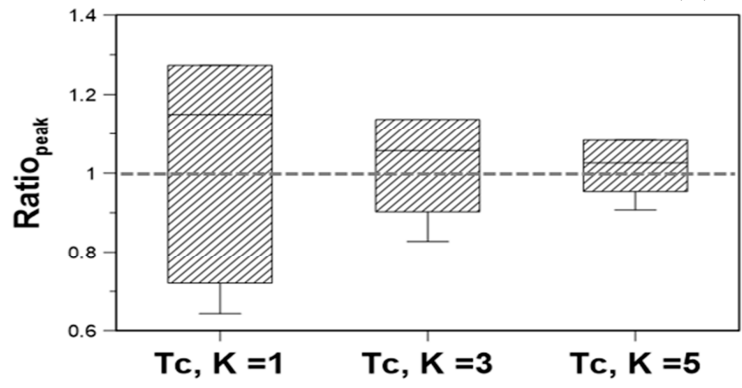

(c) $\mathrm{CN}=100$

Figure 8. Comparison of the box-plots of the runoff peak flows derived with different $\mathrm{CN}$ and $T_{\mathcal{C}}$ values.

\subsection{Preparation of the Rainfall-Runoff Model}

The result in Section 4 shows that the alternating block method produced the most similar rainfall temporal distribution to the observed. However, this result was limited, as the comparison was carried out with the redistributed observed rainfall. That is, the comparison did not consider the randomness of the observed rainfall distribution. Thus, in this part of the study, the sensitivity of the peak flow to the randomness of the rainfall temporal distribution was evaluated. As an example case, the same rainfall event in the previous section was considered.

First, a total of 10 rainfall temporal distributions were randomly generated using the rainfall distribution derived by applying the alternating block method (Figure 9). Except for the original distribution (H1), all the others seem more realistic, and similar to the observed. The same rainfall-runoff analysis was also repeated for each combination of $T_{c}, K$ and $\mathrm{CN}$. That is, nine different combinations of $T_{\mathcal{c}}, K$, and $\mathrm{CN}$ were considered in the rainfall-runoff analysis for one rainfall temporal distribution. Figure 10 compares the resulting runoff hydrographs.

The hydrographs in Figure 10 show several important factors to be considered in the analysis of the result. First, when evaluating the sensitivity to the randomness of the rainfall distribution, the effect of $T_{\mathcal{C}}$ (or the size of the basin area) is not that important. This result can be seen more clearly in the case of $\mathrm{CN}=100$. Second, particularly for the rainfall distribution with its peak at the rainfall beginning, the effect of $\mathrm{CN}$ is important. This is obvious, as most of the infiltration occurs at the beginning of a rainfall. However, if we consider only the rainfall events with their peaks on the second, third or fourth quantile, which is believed to result in some severe floods, the effect of $\mathrm{CN}$ may be excluded in the analysis of the result. Finally, it should be mentioned that the runoff peak time is directly related to the rainfall peak time. Thus, in this study, only the runoff peak flow was analyzed. 

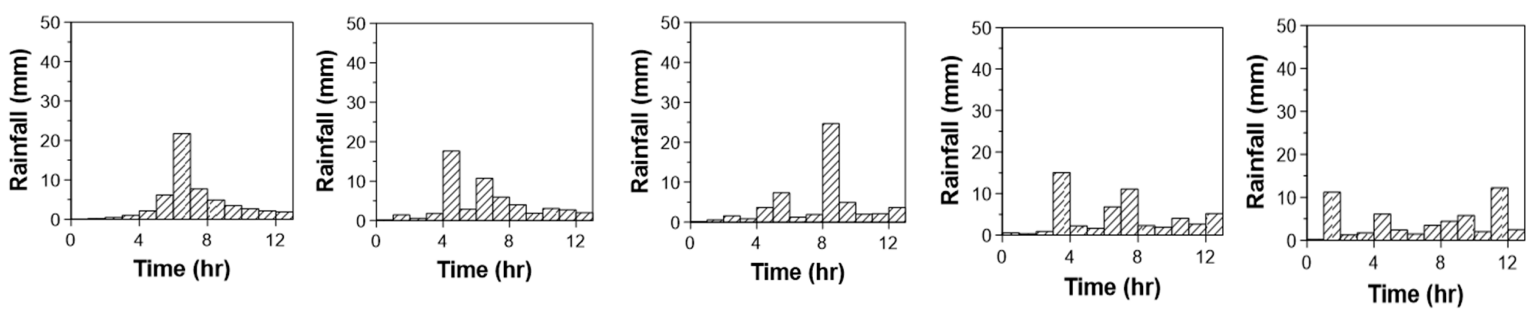

H1

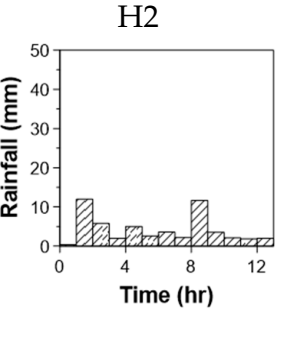

H3
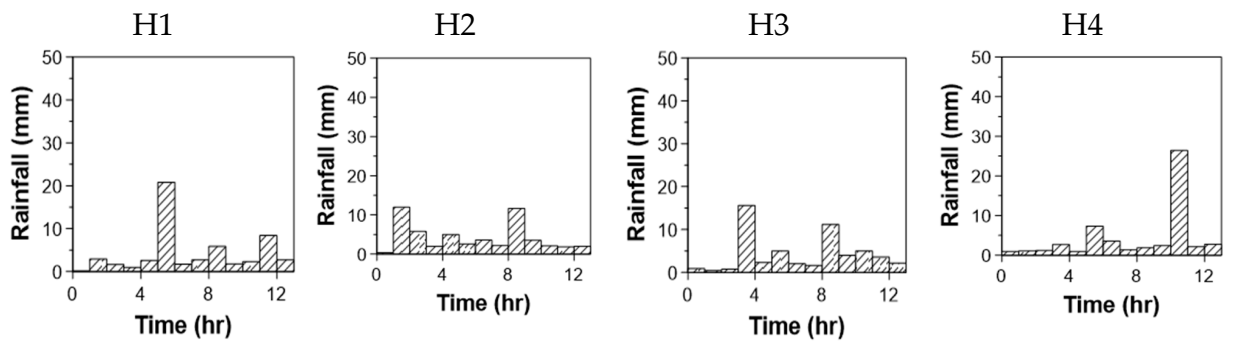

H5

H6

H7

$\mathrm{H} 8$

H9

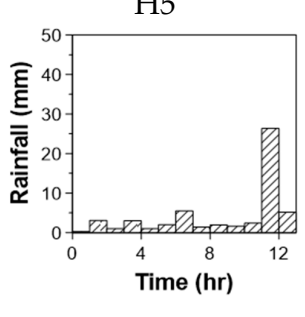

(a) $\mathrm{CN}=60$
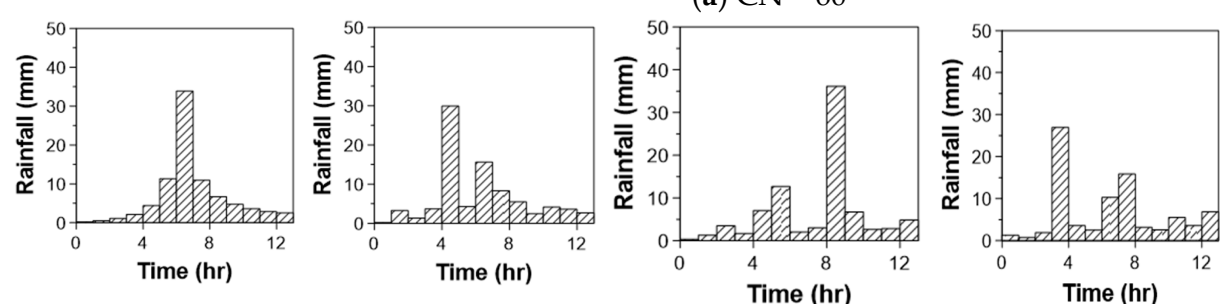

H10

H1

H2
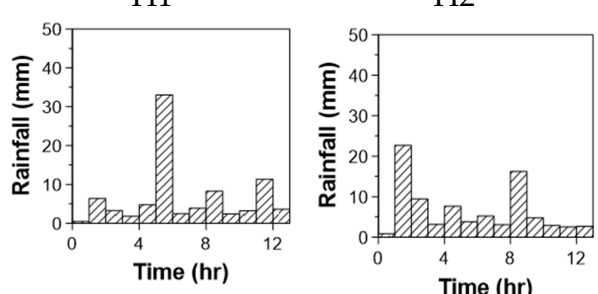

H3

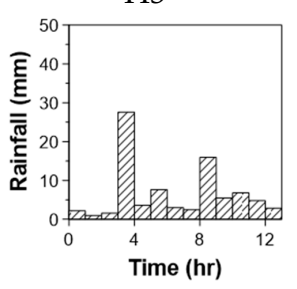

$\mathrm{H} 8$

(b) $\mathrm{CN}=80$
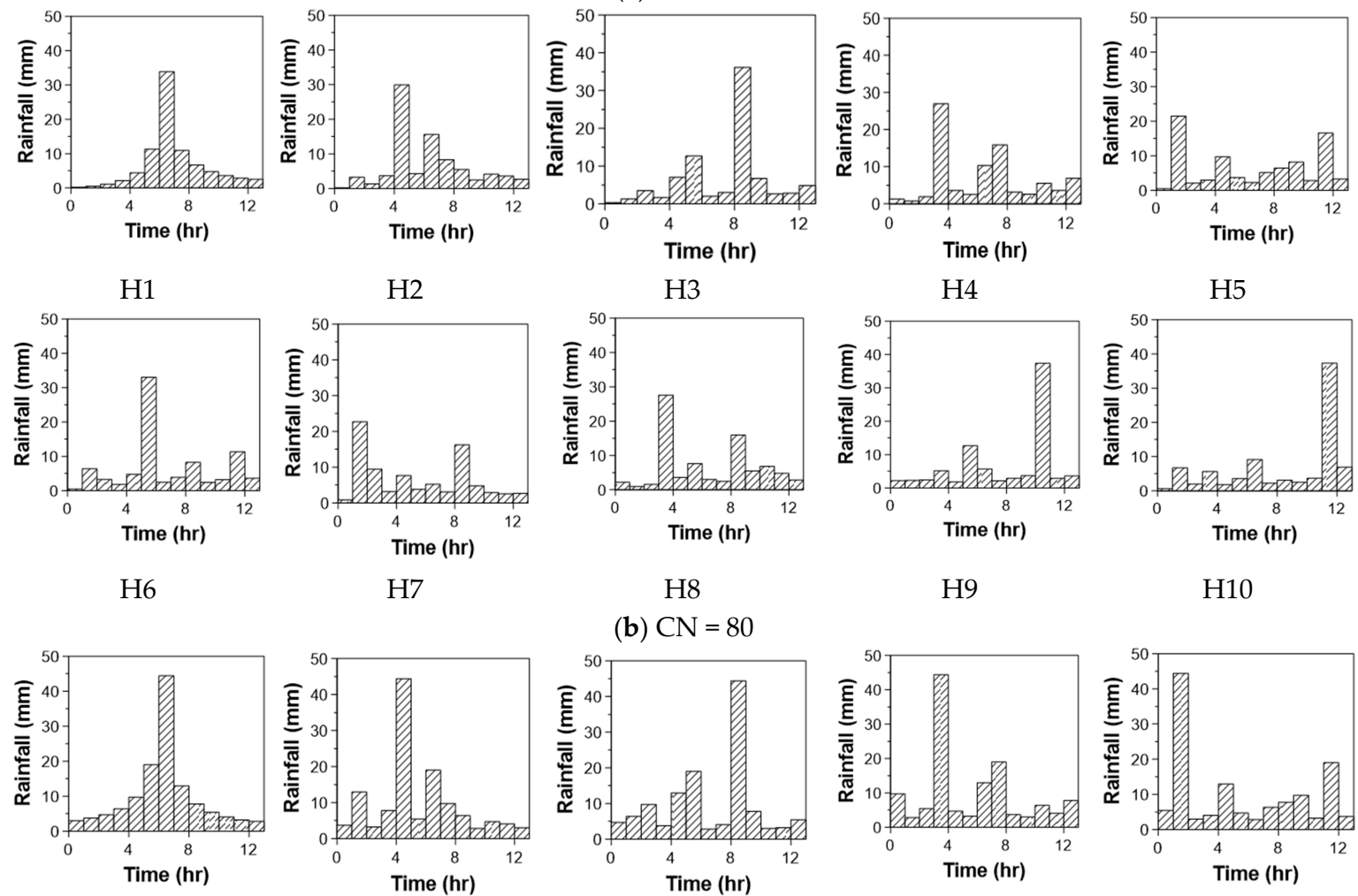

H4

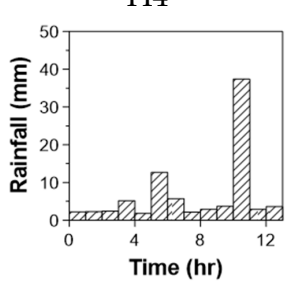

H5

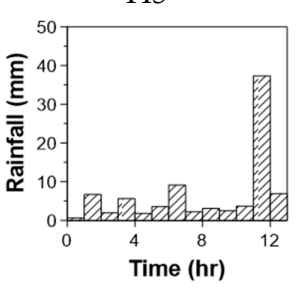

H10

H9
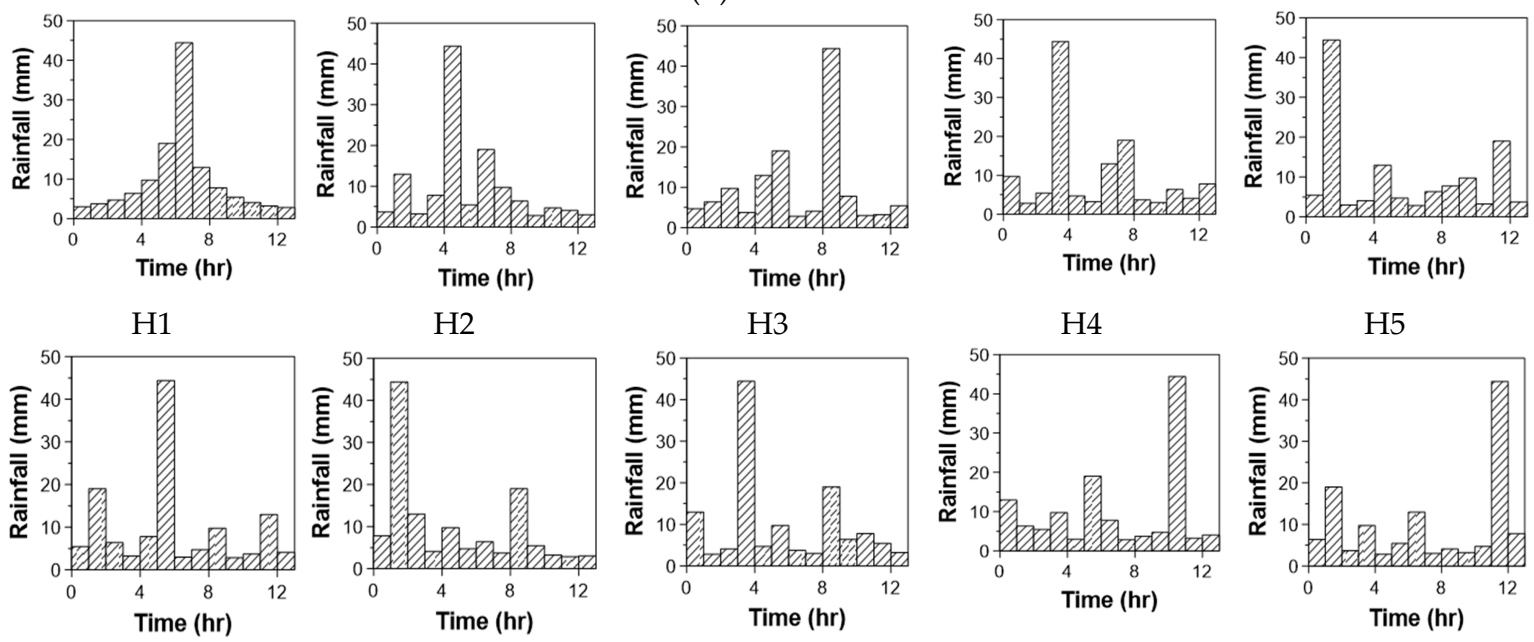

H7
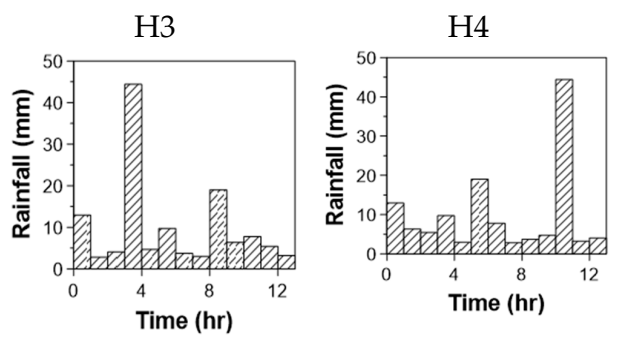

H5

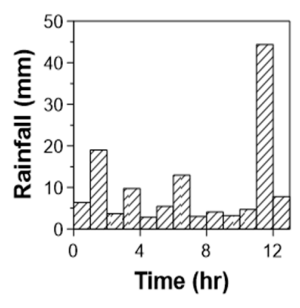

$\mathrm{H} 8$

H9

H10

(c) $\mathrm{CN}=100$

Figure 9. Randomly distributed rainfall histograms derived from the alternating block model for the annual maximum rainfall event in 1997. 

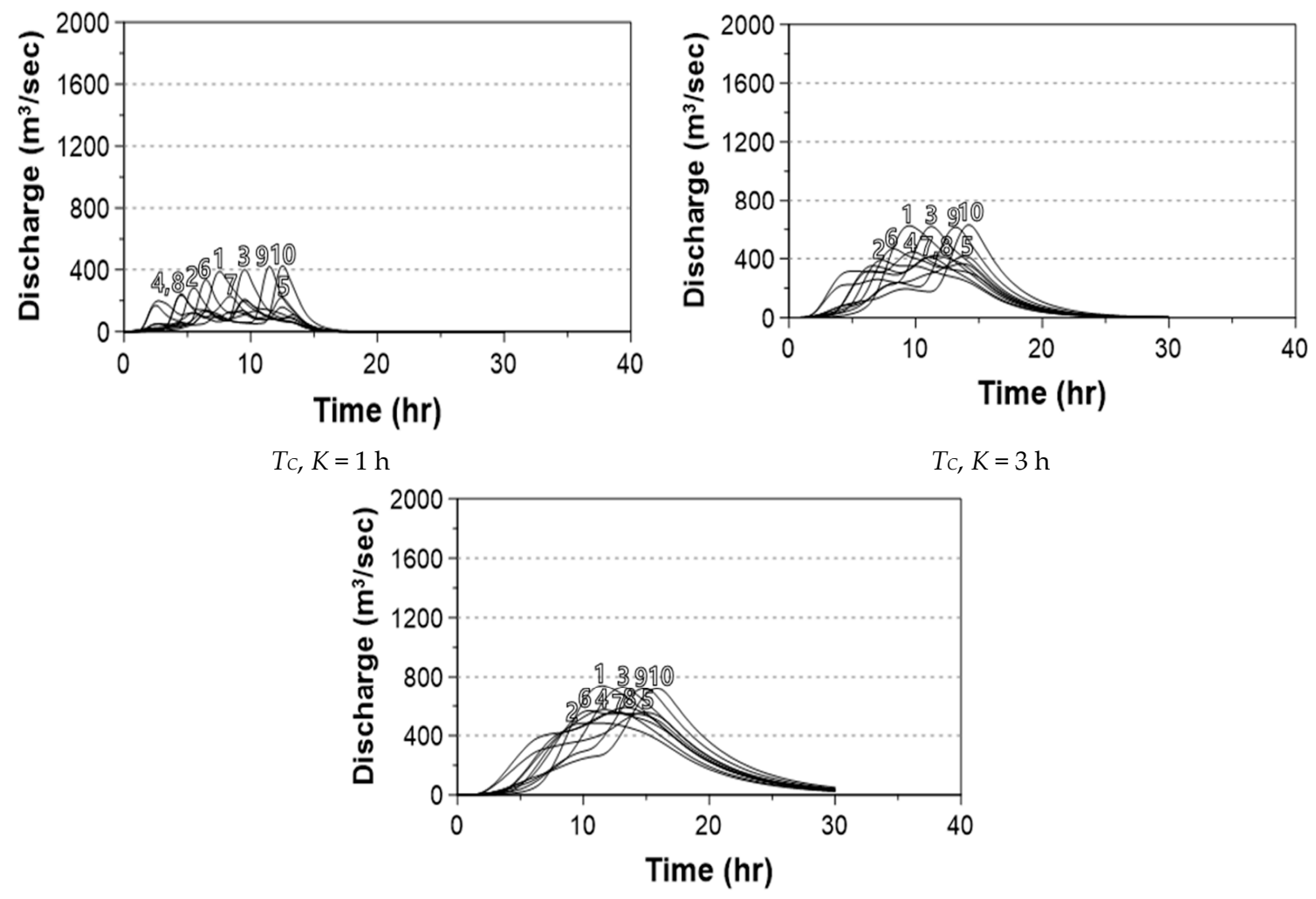

Tc, $K=5 \mathrm{~h}$

(a) $\mathrm{CN}=60$

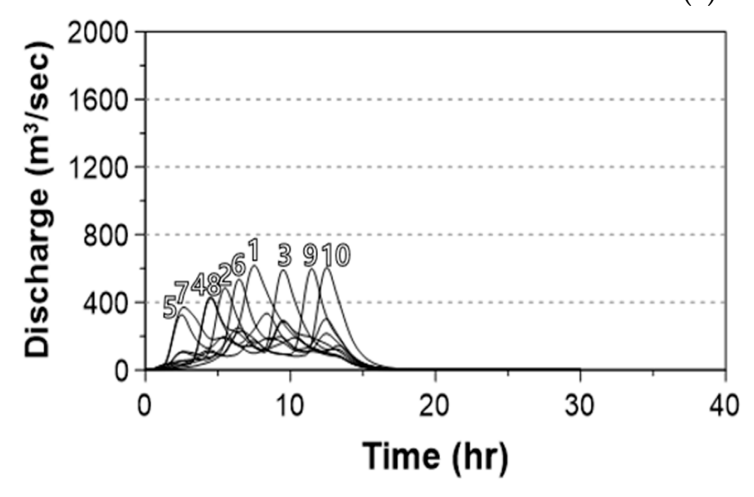

$T c, K=1 \mathrm{~h}$

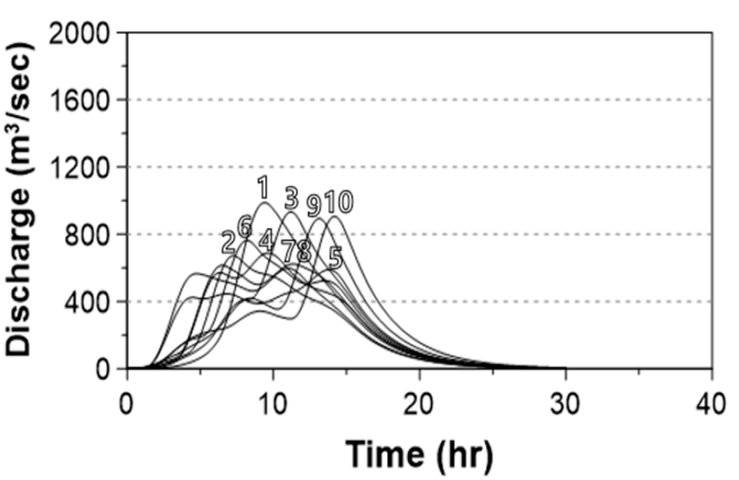

$T_{C}, K=3 \mathrm{~h}$

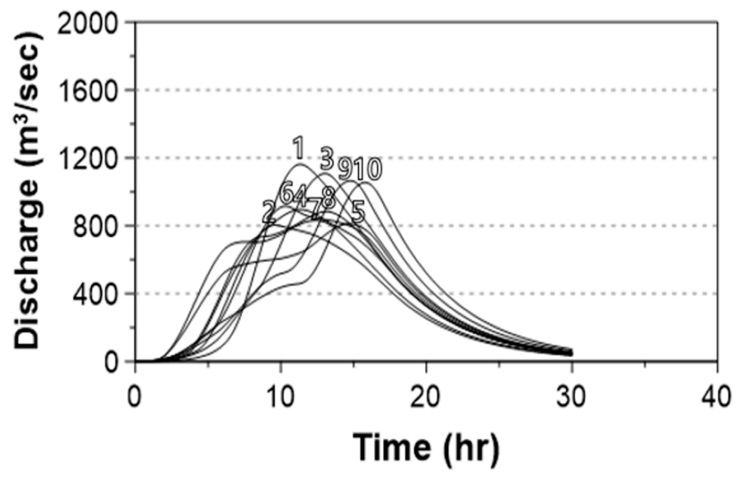

$T_{C}, K=5 \mathrm{~h}$

(b) $\mathrm{CN}=80$

Figure 10. Cont. 


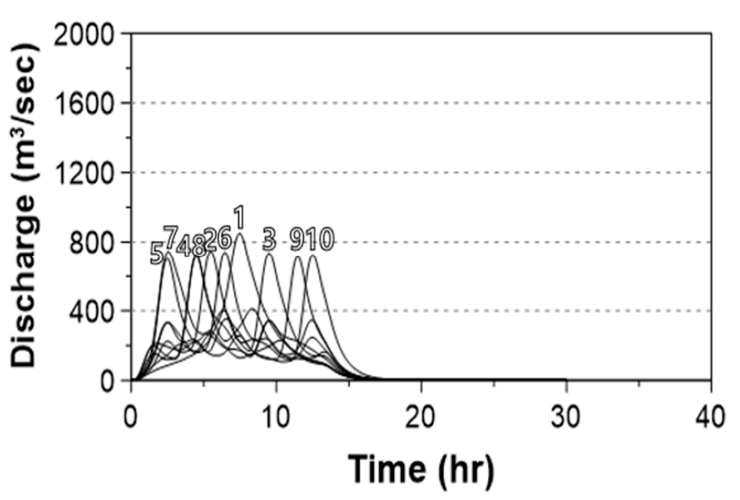

$T_{\mathrm{C}}, K=1 \mathrm{~h}$

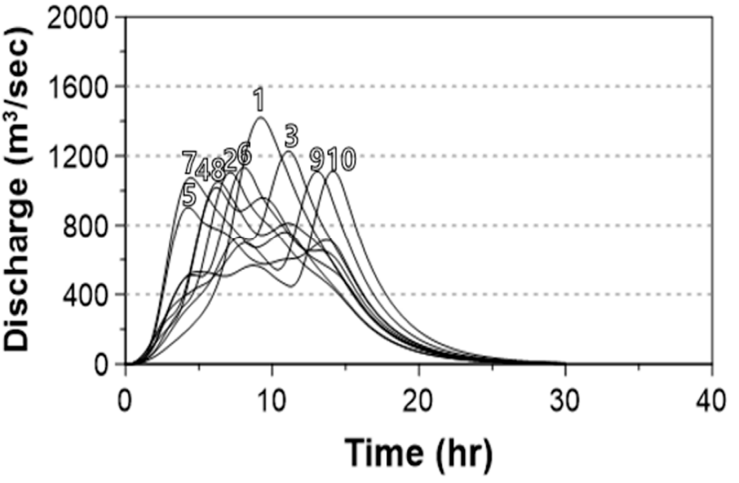

$T_{C}, K=3 \mathrm{~h}$

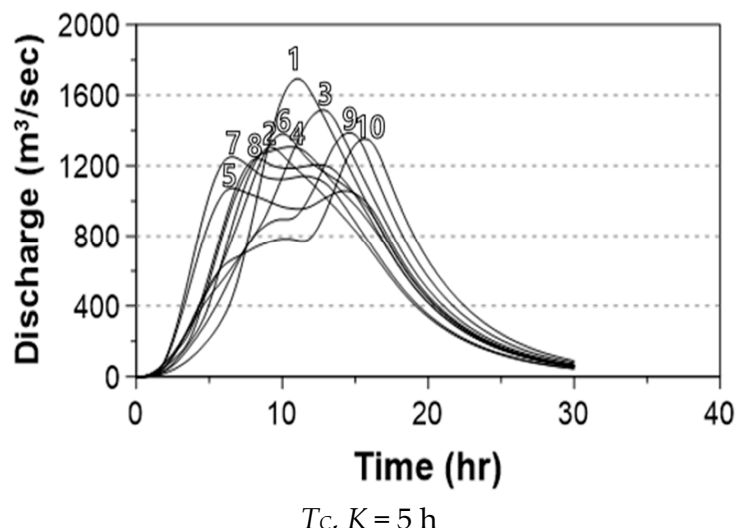

(c) $\mathrm{CN}=100$

Figure 10. As for Figure 7, but with the randomly distributed rainfall histograms in Figure 9.

Under the above assumptions regarding considering the rainfall distributions with their peaks in the second, third, or fourth quantile, we derived the following results. First, the highest peak flow was produced for the rainfall distribution $\mathrm{H} 1$, i.e., the original distribution. Other random rainfall distributions produced more or less the same peak flow. This result could be seen more clearly for the case of $\mathrm{CN}=100$. That is, under the condition of saturated soil, a very well-organized rainfall distribution like the model of rainfall temporal distribution can produce higher peak flow than a random distribution.

However, under the condition of smaller $\mathrm{CN}$ values, this effect of well-organized rainfall distribution became smaller. For the case of $\mathrm{CN}=60$, no obvious high peak flow could be found for any case of concentration times. All the small peak flows were generated by the rainfall distribution with their peak in the first quantile (i.e., $\mathrm{H} 5$ and H7). This result was also the case for $\mathrm{CN}=80$. Overall, the sensitivity of the peak flow to the randomness of rainfall temporal distribution seemed to be small. This result can also be confirmed by the box plots (Figure 11) of the Ratio peak defined by Equation (11).

The box plots in Figure 11 show several important features of the randomness of the rainfall distribution and its effect on the runoff peak flow. First, when the $\mathrm{CN}$ was high (i.e., $\mathrm{CN}=100$ in this study), for $T_{c}=1 \mathrm{~h}$, no sensitivity of the peak flow to the randomness of the rainfall temporal distribution was found. For the case of $T_{c}=3 \mathrm{~h}$ and $T_{c}=5 \mathrm{~h}$, the result was a bit higher, but still only a small sensitivity was found. On the other hand, when the $\mathrm{CN}$ was small, the sensitivity of the peak flow to the randomness of the rainfall temporal distribution was found to be very high. This was basically because the effect of infiltration on the effective runoff became significant. However, as $T_{c}$ increased, this sensitivity became smaller. 


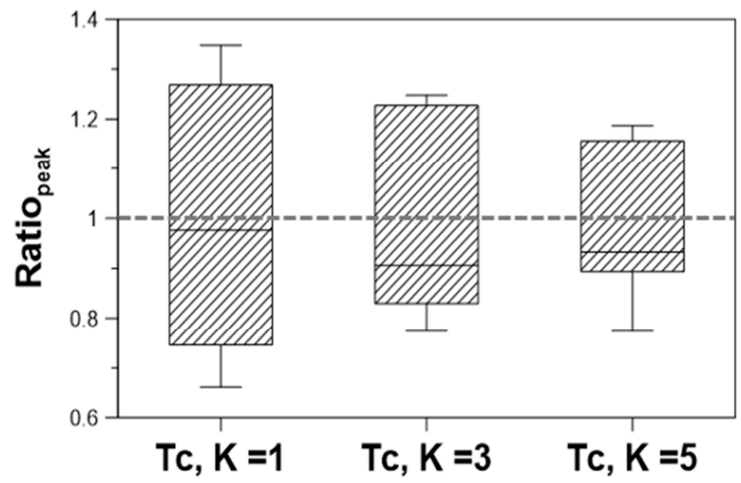

(a) $\mathrm{CN}=60$

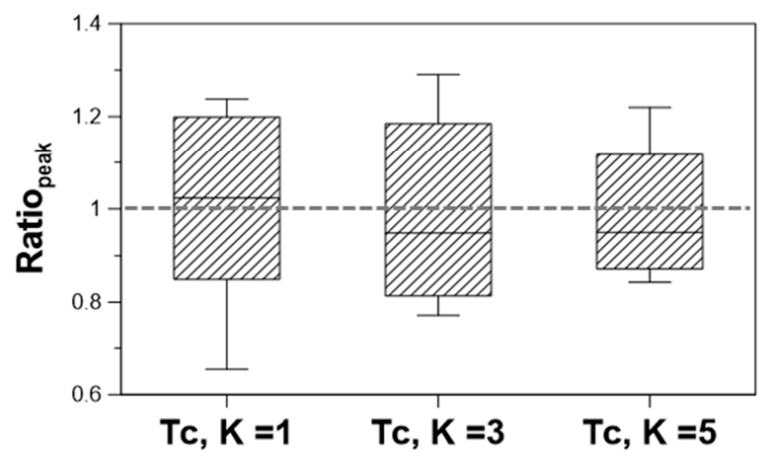

(b) $\mathrm{CN}=80$

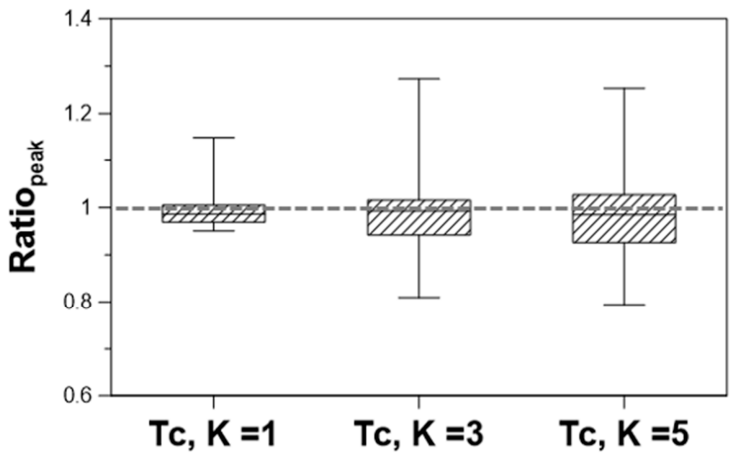

(c) $\mathrm{CN}=100$

Figure 11. As for Figure 8, but with the randomly distributed rainfall histograms in Figure 9.

Overall, it could be concluded that when the $\mathrm{CN}$ is small, the effect of the randomness of the rainfall temporal distribution on the runoff peak flow was found to be significant. The infiltration, rather than the rainfall temporal distribution, played an important role in controlling the runoff peak flow. Thus, when the effect of the infiltration was small (or the $\mathrm{CN}$ value was high), the sensitivity of the runoff peak flow to the rainfall temporal distribution became insignificant. This situation was able to be obtained in urban basins or saturated basins.

Additionally, it is also important to compare the sensitivity to the randomness and the model of rainfall temporal distribution. By comparing Figures 8 and 11, it can be easily concluded that the sensitivity of the runoff peak flow to the model of rainfall temporal distribution was much higher. With regard to the flooding condition, i.e., under the condition of high CN values in urban basins and saturated natural basins, the sensitivity of the runoff peak flow to the randomness of the rainfall temporal distribution was insignificant. Even when the $\mathrm{CN}$ values were small, the sensitivity of the runoff peak flow to the randomness of the rainfall temporal distribution was minimal, unless the rainfall peak was located in the first quantile.

\section{Summary and Conclusions}

Although rainfall temporal distribution models are generally used in hydrological practice, it is not easy to select the best model among the many models available. This is basically because, as the model shows, the observed rainfall distribution is rather random, not systematic, which prevents valid comparison. This study focused on this point, and evaluated five models of rainfall temporal distribution (i.e., the Yen and Chow model, the Mononobe model, the alternating block method, the Huff model, and the Keifer and Chu model), with the annual maximum rainfall events selected from Seoul, Korea, from 1961 to 2016. Three different evaluation measures were considered in this study, namely the absolute difference between the rainfall peaks of the model and the observed $\left(D R_{\text {peak }}\right)$, the root mean square error (RMSE), and the pattern correlation coefficient $(R)$. Additionally, 
the $D R_{\text {peak }}$ was standardized by dividing it by the observed rainfall peak $\left(S D R_{\text {peak }}\right)$, and RMSE by the mean rainfall intensity (SRMSE).

Three different cases were considered for the comparison of the model and the observed rainfall temporal distribution. The first case (Case 1) compared the model and the observed rainfall event as it was. The second case (Case 2) compared the model and the observed rainfall event, after reconciling the rainfall peak time of the model to the observed. The third case (Case 3) compared the model and the observed rainfall event after rearranging the observed rainfall temporal distribution to be most similar to the model. Finally, the sensitivity of the runoff peak flow to the model and to the randomness of the rainfall temporal distribution was analyzed. This analysis was carried out to determine whether the model or the randomness of the rainfall temporal distribution had the dominant effect on the runoff peak flow.

As a result, the $S D R_{\text {peak }}$ showed that the Yen and Chow model and the Huff model significantly underestimated the rainfall peak, while the Mononobe model overestimated it. Of the five models considered in this study, the Keifer and Chu model produced the most similar rainfall peak to the observed. On the other hand, the smallest SRMSEs were estimated for the Yen and Chow model and the alternating block method. The value of $R$ was larger for the alternating block method, but smaller for the Yen and Chow model and the Huff model. In particular, in Case 3, the alternating block method showed the smallest SRMSE and largest $R$, which indicated that it was the most similar model to the observed rainfall temporal distribution. Overall, the model that best mimicked the annual maximum rainfall events observed in Seoul, Korea, was found to be the alternating block method.

The sensitivity analysis showed that the sensitivity of the runoff peak flow to the model of rainfall temporal distribution was much higher than to the randomness of the rainfall temporal distribution. In particular, under the condition of high $\mathrm{CN}$ values in urban basins and saturated natural basins, the sensitivity of the runoff peak flow to the randomness of the rainfall temporal distribution was found to be insignificant. Even in the case where the $\mathrm{CN}$ values were small, the sensitivity of the runoff peak flow to the randomness of the rainfall distribution was found to be minimal, unless the rainfall peak was located in the first quantile.

Based on the above findings, it could be concluded that, for the estimation of the runoff peak flow, the proper selection of the rainfall temporal distribution model is important. This conclusion was also supported by the result that the sensitivity to the model of rainfall temporal distribution was found to be much higher than the sensitivity to the randomness of the rainfall temporal distribution. Particularly in a small basin with high $\mathrm{CN}$ values, the importance of using a proper model of rainfall temporal distribution cannot be underestimated. This conclusion is important as it shows that any rainfall temporal distribution model may not satisfactorily mimic the observed rainfall event. A hydrological design based on any selected rainfall temporal distribution model could thus be far from the real world. To minimize the difference between the modeling and the real world, the selection of the most probable model may well be the most important factor. However, simply the comparison of the observed and model rainfall temporal distribution is not enough. A more systematic approach, as suggested in this study, can help to find the best model.

Author Contributions: C.Y. conceived and designed the idea of this research and wrote the manuscript. W.N. collected the data and conducted estimation of rainfall temporal distribution models using that data.

Funding: This work was supported by the Korea Agency for Infrastructure Technology Advancement (KAIA) grant funded by the Ministry of Land, Infrastructure and Transport (Grant 18AWMP-B083066-05).

Conflicts of Interest: The authors declare no conflict of interest.

\section{References}

1. Nouh, M.A. Effects of Rainfall Runoff Model Assumptions on Optimal Storm-Sewer System-Design. Arab. J. Sci. Eng. 1987, 12, 19-35. 
2. U.S. Soil Conservation Service (SCS). A Method for Estimating Volume and Rate of Runoff in Small Watersheds; U.S. Soil Conservation Service: Washington, DC, USA, 1973.

3. Huff, F.A. Time Distribution of Rainfall in Heavy Storms. Water Resour. Res. 1967, 3, 1007-1019. [CrossRef]

4. Jeong, J.H.; Yoon, Y.N. Design Practices for Water Resources; Goomi Press: Seoul, Korea, 2007.

5. Pilgrim, D.H.; Cordery, I. Rainfall Temporal Patterns for Design Floods. J. Hydraul. Div. ASCE 1975, 101, 81-95.

6. Yen, B.C.; Chow, V.T. Design Hyetographs for Small Drainage Structures. J. Hydraul. Div. ASCE 1980, 106, 1055-1076.

7. Chow, V.T.; Maidment, D.R.; Mays, L.W. Applied Hydrology; McGraw-Hill: New York, NY, USA, 1988.

8. Keifer, C.J.; Chu, H.H. Synthetic storm pattern for drainage design. J. Hydraul. Div. 1957, 83, 1-25.

9. Lee, K.T.; Ho, J.Y. Design hyetograph for typhoon rainstorms in Taiwan. J. Hydrol. Eng. 2008, 13, 647-651. [CrossRef]

10. Garcia-Guzman, A.; Aranda-Oliver, E. A Stochastic-Model of Dimensionless Hyetograph. Water Resour. Res. 1993, 29, 2363-2370. [CrossRef]

11. Lin, G.F.; Chen, L.H.; Kao, S.C. Development of regional design hyetographs. Hydrol. Process. 2005, 19, 937-946. [CrossRef]

12. Cheng, K.S.; Hueter, I.; Hsu, E.; Yen, H.C. A scale-invariant Gauss-Markov model for design storm hyetographs. J. Am. Water Resour. Assoc. 2001, 37, 723-735. [CrossRef]

13. Wu, S.J.; Yang, J.C.; Tung, Y.K. Identification and stochastic generation of representative rainfall temporal patterns in Hong Kong territory. Stoch. Environ. Res. Risk Assess. 2006, 20, 171-183. [CrossRef]

14. National Ocanic and Atmospheric Administration (NOAA). Precipitation-Frequency Atlas of the United States; NOAA: Silver Spring, MD, USA, 2013.

15. Chan, E.S.; Balmforth, D.; Kan, Y.; Koike, T.; Lampe, L.; Lim, K.K.; Yong, K.K. Report on Key Conclusions and Recommendations of the Expert Panel on Drainage Design and Flood Protection Measures; Singapore's National Water Agency: Singapore, 2012.

16. Ministry of Construction and Transportation (MOCT). River Maintenance Basic Plan and Instructions of River Maintenance Report; MOCT: Seoul, Korea, 2004.

17. Yin, S.Q.; Xie, Y.; Nearing, M.A.; Guo, W.L.; Zhu, Z.Y. Intra-Storm Temporal Patterns of Rainfall in China Using Huff Curves. Trans. ASABE 2016, 59, 1619-1632.

18. Nelson City Council. Maitai River Flood Hazard Mapping Modelling Report; Nelson City Council: Nelson, New Zealand, 2013.

19. Palla, A.; Gnecco, I. Assessing the urban catchment hydrologic response under different environmental scenarios. In Proceedings of the NOVATECH 2016-9th International Conference on Planning and Technologies for Sustainable Urban Water Management, Lyon, France, 28 June-1 July 2016.

20. Japan International Cooperation Agency (JICA). Technical Standards and Guidelines for Planning of Flood Control Structures; JICA: Tokyo, Japan, 2010; pp. 39-42.

21. Drainage Services Department. Stormwater Drainage Manual: Planning, Design and Management; Drainage Services Department: Hong Kong, China, 2018; Volume 26.

22. Japanese Ministry of Land, Infrastructure, Transport and Tourism (MLITT); Kanazawa, H.; Yoshitani, J.; Shintaku, S. Technical Criteria for River Works: Practical Guide for Planning; MLITT: Tokyo, Japan, 2009.

23. Al-Rawas, G.A.; Valeo, C. Characteristics of rainstorm temporal distributions in arid mountainous and coastal regions. J. Hydrol. 2009, 376, 318-326. [CrossRef]

24. Aron, G.; Wall, D.J.; White, E.L.; Dunn, C.N. Regional Rainfall Intensity-Duration-Frequency Curves for Pennsylvania. Water Resour. Bull. 1987, 23, 479-485. [CrossRef]

25. Guo, J.C.Y.; Hargadin, K. Conservative Design Rainfall Distribution. J. Hydrol. Eng. 2009, 14, 528-530. [CrossRef]

26. Kimoto, A.; Canfield, H.E.; Stewart, D. Comparison of Synthetic Design Storms with Observed Storms in Southern Arizona. J. Hydrol. Eng. 2011, 16, 935-941. [CrossRef]

27. Nguyen, V.T.V.; Desramaut, N.; Nguyen, T.D. Optimal rainfall temporal patterns for urban drainage design in the context of climate change. Water Sci. Technol. 2010, 62, 1170-1176. [CrossRef] [PubMed]

28. Ministry of Construction and Transportation (MOCT). 1999 Report on the Development of Water Resources Management Techniques: Design Rainfall Temporal Distribution; MOCT: Seoul, Korea, 2000. 
29. Ministry of Land, Transport and Maritime Affairs (MLTM). Research on the Improvement of Probability Rainfall; MLTM: Seoul, Korea, 2011.

30. Choi, S.; Joo, K.; Shin, H.; Heo, J. Improvement of Huff's Method Considering Severe Rainstorm Events. J. Korea Water Resour. Assoc. 2014, 47, 985-996. [CrossRef]

31. Joo, J.; Lee, J.; Jo, D.; Jun, H.; Kim, J. Development of a Rainfall Time Distribution Model for Urban Watersheds. J. Korea Water Resour. Assoc. 2007, 40, 655-663. [CrossRef]

32. Knapp, H.V.; Terstriep, M.L. Effects of Basin Rainfall Estimates on Dam Safety Design in Illinois; Illinois State Water Survey: Champaign, IL, USA, 1981; pp. 14-22.

33. Ward, A.B.; Bridges, T.; Barfield, B. An evaluation of hydrologic modeling techniques for determining a design storm hydrograph. In Proceedings of the International Symposium on Urban Storm Runoff, University of Kentucky, Lexington, Kentucky, 28-31 July 1980; pp. 28-31.

34. Lee, J.K.; Chu, H.J. Time distribution characteristics of an annual maximum rainfall according to rainfall durations using Huff's method. J. Korean Soc. Civ. Eng. 2006, 26, 519-528.

35. Park, M.; Yoo, C.; Kim, H.; Jun, C. Bivariate frequency analysis of annual maximum rainfall event series in Seoul, Korea. J. Hydrol. Eng. 2014, 19, 1080-1088. [CrossRef]

36. Park, C.; Yoo, C. Review of parameter estimation procedure of Freud bivariate exponential distribution. J. Korea Water Resour. Assoc. 2012, 45, 191-201. [CrossRef]

37. Loveridge, M.; Babister, M.; Retallick, M. Australian Rainfall and Runoff Revision Project 3: Temporal Patterns of Rainfall; Department of Industry, Innovation and Science: Canberra, Australia, 2015.

38. Mockus, V. National Engineering Handbook: Section 4, Hydrology; U.S. Department of Agriculture: Washington, DC, USA, 1965.

(C) 2018 by the authors. Licensee MDPI, Basel, Switzerland. This article is an open access article distributed under the terms and conditions of the Creative Commons Attribution (CC BY) license (http:/ / creativecommons.org/licenses/by/4.0/). 